\title{
LOS COMUNEROS, EL ABOGADO Y EL SENADOR. CULTURA POLÍTICA Y ORDEN LIBERAL A FINES DEL PORFIRIATO ${ }^{1}$
}

\author{
José Alfredo Rangel Silva \\ El Colegio de San Luis
}

Ecomunidades de Santa María Acapulco, San Antonio de
los Geptiembre de 1906 los "cabezas de familia de las
cadas en el partido de Hidalgo, San Luis Potosí), ${ }^{2}$ junto con
otros "cientos" de indígenas, asesorados legalmente por el
abogado Wistano Luis Orozco, firmaron un ocurso dirigido

Fecha de recepción: 16 de enero de 2014

Fecha de aceptación: 15 de mayo de 2014

\footnotetext{
${ }^{1}$ Agradezco los comentarios y sugerencias de los dictaminadores anónimos de Historia Mexicana. Como siempre, los errores y omisiones son de mi total responsabilidad.

${ }^{2}$ En esa época San Luis Potosí estaba dividido en 13 partidos; el partido de Hidalgo corresponde a la parte centro sur de lo que en la actualidad es la zona media del estado. En el siglo XviII a ese espacio se le llamaba la pamería, por el predominio demográfico del grupo pame. Es importante entender que la zona media nunca ha sido considerada parte de la Huasteca potosina, aunque sean espacios contiguos. Consúltese EscoBAR, "Estudio introductorio", p. 26.
} 
a Porfirio Díaz en un intento desesperado por defender las tierras de las comunidades. ${ }^{3}$ Esos pueblos existían desde el siglo XVII, cuando fueron fundados como misiones franciscanas que congregaron a los indígenas pames. ${ }^{4}$ En la última década del porfiriato enfrentaban un momento especialmente difícil debido a los procesos de desamortización de bienes comunales, por el desconocimiento legal de cualquier corporación como sujeto de derecho, por la acción de las compañías deslindadoras y por los efectos de la ley de terrenos baldíos de $1894 .^{5}$

Wistano Luis Orozco tenía mucha experiencia en asuntos legales sobre la propiedad de la tierra. Había trabajado por casi una década para varias compañías deslindadoras en el vecino estado de Zacatecas, había publicado en 1895 un voluminoso estudio sobre la legislación alrededor de los terrenos baldíos en México, ${ }^{6}$ y había representado a varios clientes en

${ }^{3}$ CCJSLP, JD, A, núm. 51, Juicio de amparo solicitado por el Lic. Wistano Luis Orozco contra el juez de primera instancia de Alaquines, por orden de aprehensión, México, marzo de 1907.

${ }^{4}$ Por ubicarse en la frontera las misiones tenían un fundo legal de tres leguas en cuadro, que por cédula real se redujo a una legua en cuadro al finalizar el siglo Xvir. Los estancieros siempre alegaron que otra cédula real establecía ese fundo legal en solo 600 varas en cuadro. La confusión de medidas, la simultánea fundación de estancias y misiones, la perene indefinición de límites entre propiedades, y la violencia como forma de resolución de problemas, crearon una estructura de la propiedad en constante conflicto. Consúltese Rangel Silva, "Pames, estancieros", pp. 225-266.

${ }^{5}$ Durante el porfiriato se aplicaron la ley de 1863 sobre terrenos baldíos y la ley de 1894. También fue cuando se deslindaron y privatizaron más tierras públicas y baldíos: $96 \%$ del total de hectáreas transferidas lo fue entre 1877 y 1908. Holden, Mexico and the Survey of Public Lands, pp. 9, 16.

${ }^{6}$ Consúltese Orozco, Legislación y jurisprudencia sobre terrenos bal- 
San Luis Potosí, tanto de la élite como pequeños propietarios. Orozco había defendido exitosamente a los condueños del predio conocido como de los Moctezuma en 1901-1902, cuando consiguió que la Suprema Corte de Justicia les restituyera la posesión frente a poderosos políticos estatales y propietarios que intentaron despojarlos de forma ilegal y violenta. ${ }^{7}$ Con tales antecedentes los representantes de las comunidades lo buscaron en esos años. Los de Guayabos desde enero de 1906, y los de Santa María Acapulco desde 1905, por lo menos, le plantearon su problema y lo convencieron de tomar el asunto de forma legal. Era la primera vez que Orozco trabajaba con clientes indígenas. Bajo su dirección los representantes de las cinco comunidades firmaron el ocurso o memorial que resumía los agravios padecidos a lo largo de los años, supuestamente acentuados por las acciones del senador Antonio Arguinzóniz, dueño de la hacienda de Tanlacú. Arguinzóniz era senador de la República por Querétaro y un gran propietario en San Luis Potosí. Era por su parentesco, ${ }^{8}$ su fortuna y su posición política, un dechado de la élite no sólo de la región sino del mismo régimen porfirista.

El ocurso de 1906 y el proceso judicial que desató resultan interesantes por varias razones: primero porque el memorial muestra una narrativa de los comuneros sobre sus propie-

díos; otras de sus publicaciones fueron Orozco, Los negocios sobre tierras públicas; y Orozco, Los ejidos de los pueblos.

7 Ankerson, El candillo agrarista, pp. 20, 21; Gutiérrez, "El condueñazgo de los Moctezuma”, pp. 236-62. Ese conflicto legal se prolongó hasta 1911.

${ }^{8}$ Sus hermanos Mariano y Joaquín vivían en San Luis Potosí, y eran igualmente grandes propietarios. Consúltese FALCón, Revolución y caciquismo, pp. 24, 25. 
dades, segundo porque ese esfuerzo de defensa de tierras y derechos fue colectivo, al unir sus esfuerzos las cinco comunidades. Tercero, el documento y el proceso son un ejemplo de la cultura política de la última década del porfiriato y, finalmente, porque permiten al historiador captar las formas cotidianas, los entretelones "a ras de suelo" " de las dinámicas de negociación, y de imposición, de los elementos del orden derivado de la modernidad liberal entre los diferentes actores.

La narrativa histórica ${ }^{10}$ sobre la posesión y propiedad de la tierra se hizo con base en los títulos coloniales de los pueblos misión; sostenía el derecho legal de cada comunidad a esas tierras y a las que habían perdido en el curso de los años. Esto se parece a otros casos analizados para México y América Latina en los que la búsqueda, la invención y la preservación de documentos históricos de carácter legal son rasgos persistentes de los pueblos indígenas en la defensa de sus derechos por sus tierras. ${ }^{11}$ Pero la narrativa en el ocurso de

9 Tomo la frase de FALcón, "Desamortización a ras de suelo", que la usa como metáfora de la realidad cotidiana que enfrentaban las clases populares o subalternas.

${ }^{10}$ Entiendo por narrativa una trama articulada, en el plano del discurso, que reúne fines, causas y elementos en una unidad temporal dotada de sentido y que engloba una acción completa. Tomo esta definición de Paul Ricoeur, quien desarrolló una reflexión ontológica y epistemológica sobre la narrativa y el texto histórico. Consúltese Ricoevr, Tiempo y narración, I, pp. 31, 39-40 y 80-82. Esta perspectiva pone el acento en el discurso como texto al mismo tiempo que no reduce el texto al artefacto escrito. La narrativa estaba sustentada en la temporalidad histórica tal como los pames la entendían; es decir, no sigue una trama lineal ni consecutiva, más bien da saltos temporales y selecciona episodios considerados importantes en torno del asunto principal: la defensa colectiva de las tierras.

${ }^{11}$ Pueden consultarse los siguientes ejemplos: LIRA, Comunidades indí- 
1906 era algo más que la consabida "cantaleta" de los pueblos respecto de sus tierras: era el resultado de la capacidad de acción conjunta de cinco comunidades en un momento en que las leyes nacionales y estatales desconocían cualquier tipo de acción legal; comunidades que compartían un pasado común, una referencia étnica y su lucha por la sobrevivencia.

Los representantes de las comunidades buscaron resolver los problemas de las tierras con las reglas legales del orden liberal, ${ }^{12}$ pero sus intentos fueron más o menos frustrados. Así que, aconsejados por Orozco, decidieron apelar a la instancia política más alta, convirtiendo sus demandas sobre sus tierras en un asunto tanto político como jurídico. Su intento ejemplifica la mezcla de formas antiguas y modernas en la cultura política de finales del porfiriato, por lo menos en el partido de Hidalgo, San Luis Potosí. Los conceptos de cultura política y de comunidad son ampliamente utilizados por los historiadores del siglo xIx, $\mathrm{y}$ ambos pocas veces son definidos de forma explícita. ${ }^{13}$ Entiendo cultura política como el conjunto de prácticas y discursos mediante el cual grupos e individuos articulan, negocian e implementan demandas de

genas frente a la ciudad de México. Más recientemente MARINO, "La modernidad a juicio"; "Ahora que Dios nos ha dado padre", pp. 13531410; Arrioja Díaz Viruell, "Conflictos por tierras y pesquisas documentales”, pp. 185-213.

12 Tómese orden liberal como el conjunto de transformaciones del régimen político, legal y económico que se inaugura en México con la vigencia de la Constitución de 1857 y de acuerdo con una tendencia latinoamericana de la época. Carmagnani, "Introducción”, pp. 1, 2.

${ }^{13}$ Consúltese Formisano, "The Concept of Political Culture”, pp. 393426 , que se refiere al problema de definir cultura política; lo mismo aplica para el concepto de comunidad. 
tipo político unos a otros. ${ }^{14}$ En la cultura política gobiernos y sociedades dan forma a la legitimidad del orden vigente y de las acciones dentro de ese orden, ${ }^{15}$ en una dinámica donde conviven viejos y nuevos elementos en constante interacción y negociación. La cultura política del porfiriato presentaba una fachada dominada por los valores del orden liberal, dentro de la cual existían elementos no liberales. Los análisis de la historia política se han concentrado en revisar la participación de las élites y de las clases medias en la conformación de una nueva nación y una cultura política mexicana en el siglo xix. En cuanto a los grupos “populares” o clases bajas, hay una tendencia a analizar motines, revueltas y movilizaciones callejeras del "populacho urbano" a lo largo del siglo XIx, ${ }^{16}$ en tanto que los trabajos sobre indígenas y campesinos han preferido la primera mitad del siglo XIX, cuando es más aparente el proceso de transición de las viejas

${ }^{14}$ Sigo la definición de BAKer, Inventing the French Revolution, p. 4, porque todavía es la más completa y ha sido citada frecuentemente por los historiadores interesados en el análisis de la cultura política, por ejemplo Guardino, Peasants, Politics; Connaughton, "Introducción", p. 9; Silva Prada, "Las manifestaciones políticas indígenas", pp. 75-135; Guardino, El tiempo de la libertad, p. 14. La definición de Baker es esencialmente lingüística pero, como él mismo aclaró, la perspectiva lingüística no anula ni rechaza la posibilidad de la agencia.

${ }^{15}$ Una definición diferente de cultura política puede verse en GUARISCO, "Indios, cultura y representación política”, p. 168. Para el origen del concepto consúltese Somers, "What's Political or Cultural about Political Culture", pp. 113-144; Formisano, "The Concept of Political Culture", pp. 393-426.

${ }^{16}$ Por ejemplo Ríos ZúÑIga, "Popular Uprising and Political Culture in Zacatecas", pp. 499-536; PÉrez Toledo, "Movilización social y poder político", pp. 335-367; Guardino, El tiempo de la libertad. Con un tono distinto, PicatTo, "El populacho y la opinión pública". 
formas coloniales a la modernidad, ${ }^{17}$ así como la época de la reforma liberal, cuando esos grupos intervinieron de un lado o del otro en las grandes cuestiones políticas nacionales. Destacan unos cuantos trabajos dedicados a la segunda mitad del siglo xIx, en especial los realizados por Romana Falcón desde la perspectiva de la subalternidad y la resistencia. ${ }^{18}$

Este trabajo propone revisar las formas como algunos actores "populares" (los representantes de las comunidades y los comuneros) participaban en la conformación de la cultura política en el porfiriato desde el ámbito local, a pesar de que el orden liberal los colocaba fuera del entramado legal. Entiendo por comunidad - en el sentido usado por los propios representantes para evocar el conjunto de residentes de cada pueblo y sus diferentes rancherías - a los individuos que compartían una identidad local además del interés por conservar el acceso a un determinado conjunto de recursos como las tierras, los montes, los bosques, etc., que tradicionalmente consideraban suyos. No es una abstracción contemporánea sobre elementos del pasado, ${ }^{19}$ sino un concepto utilizado y asumido por representantes y repre-

17 Una corriente historiográfica inspirada en los trabajos de Antonio Aninno se ha concentrado en el impacto de la constitución gaditana en los pueblos de indios, en especial en el cambio de vasallo a ciudadanos, las elecciones de ayuntamientos, y la mezcla de elementos políticos de antiguo régimen con los nuevos. Un ejemplo reciente es de GuARIsco, "Indios, cultura y representación política", pp. 167-221.

18 Aquí nombro algunos de sus trabajos más recientes Falcón, "Subterfugios y deferencias”, pp. 125-143; "Litigios interminables”, pp. 81-97; "Indígenas y justicia durante la era juarista", pp. 123-150; "Desamortización a ras de suelo".

19 Silva Prada, "Las manifestaciones políticas indígenas", pp. 76-77, apela a esa abstracción para distinguir los pueblos de indios coloniales de sus contrapartes decimonónicas. 
sentados como mecanismo de autoidentificación y de diferenciación con los otros actores. ${ }^{20}$ Esas comunidades no eran homogéneas ni unidades cohesivas, pues como se verá en este trabajo, divisiones, disensiones y negaciones eran frecuentes. La bibliografía sobre comunidad y comunidades es enorme y, como en el caso de la cultura política, no siempre se define el concepto. ${ }^{21}$

Desde el punto de vista político el memorial de los pames no constituyó parte de una revuelta o motín, ni tuvo como problema principal las elecciones locales en las comunidades; tampoco representa una negociación entre un liderazgo de élite y sus bases populares. Era un intento de negociación con la autoridad superior del país, con base en su afirmación de que las tierras que peleaban debían considerarse "pro indiviso", ${ }^{22}$

${ }^{20}$ Los comuneros eran los integrantes de la comunidad autoidentificados de esa manera.

${ }^{21}$ Como ejemplos, R. Falcón, "Litigios interminables", pp. 81-83; Escobar Ohmstede, "La ciudadanía en México", pp. 65-80 y Radding, "Paisajes poscoloniales: las comunidades", no definen el término aunque en cada texto se puede entender de qué se trata. Recientemente Kourí, Un pueblo dividido, p. 198, define comunidad indígena decimonónica "en sentido político organizado y unificado", y supone que deriva del concepto fiscal colonial (bienes de comunidad, caja de comunidad), pero ya sin esos referentes (véase la p. 161). Para el concepto colonial consúltese Menegus, "La desamortización de bienes comunales", pp. 7-27.

${ }^{22}$ Según el Diccionario Panhispánico de dudas, de la Real Academia Española, pro indiviso significa "sin dividir" y se usaba "en referencia a los bienes que se poseen en comunidad, sin repartir: 'Hipotecada una finca pro indiviso por los condueños' (Ley hipotecaria [Esp. 1909]); 'Hay comunidad cuando la propiedad de una cosa o de un derecho pertenece pro indiviso a varias personas' (Código civil [Esp. 1889])". http://lema.rae.es/ $\mathrm{dpd} / \mathrm{srv} / \mathrm{search}$ ?key=indiviso El pro indiviso puede darse de forma intencionada, al adquirir una parte de un inmueble o una acción, o de forma accidental, como en el caso de una herencia o un divorcio. 
es decir, condueñazgos. ${ }^{23}$ Querían que Porfirio Díaz escuchara sus quejas, interviniera para medir y regresarles sus tierras y quitara de la zona a los jueces antiindígenas, mediante un documento donde el viejo formato colonial de peticiones apelando a la autoridad del rey se mezcla con los lenguajes liberales. Mientras defendían sus tierras con base en las formas jurídicas modernas, también buscaban que la autoridad política les permitiera recuperar dignidad y viabilidad, en medio de un sistema político jurídico anticorporativo que, además, percibían como antiindígena. ${ }^{24}$

Es importante remarcar que no me concentro en el análisis de la estructura agraria en el partido de Hidalgo, pues aunque las disputas sobre las tierras son el eje central de todo el proceso, me interesa dilucidar cómo las élites, los abogados y los comuneros se movían en la cultura política, la construían y negociaban. Por eso es importante revisar las acciones lega-

${ }^{23}$ Se puede definir al condueñazgo como una propiedad agraria que pertenecía a varios dueños. Escobar y GutiérRez, "El liberalismo y los pueblos", p. 256. En sentido económico es una sociedad propietaria de un predio, que usufructuaba directamente o por medio del arrendamiento, y que contaba con accionistas, reglamentos, cuotas y membresías. Escobar y Gutiérrez, "El liberalismo y los pueblos, pp. 280-286; también Kourí, Un pueblo dividido, 208-272. En sentido jurídico es una propiedad pro indivisa, al no registrarse una división legal del terreno entre los dueños. Así lo maneja Wistano L. Orozco, y es el sentido en que se usará en este trabajo. Para ahondar en el concepto véase Aguilar-Robledo, "Los condueñazgos del oriente de San Luis Potosí”, pp. 151-189; GutiÉRREZ, "El condueñazgo de los Moctezuma”, pp. 236-262. Entre otros, Serna, Manuel Peláez y la vida rural, pp. 46-88, señala su existencia en el norte de Veracruz.

${ }^{24}$ Coincido con Silva Prada, "Las manifestaciones políticas indígenas", p. 79, que plantea que las manifestaciones políticas de los pueblos y comunidades no se reducían a las peticiones sobre sus tierras. 
les del abogado (Orozco) y del senador (Arguinzóniz) como ejemplos de las aristas, sinuosidades y penumbras que implicaba el orden jurídico liberal, su implementación y sus consecuencias. Este caso nos permite preguntar ¿cómo se construye la cultura política?, ¿qué elementos la componen?, ¿cuál es el peso de la legislación liberal en la cultura política?

Figura 1

PARTIDO DE HIDALGO, SLP, EN 1900

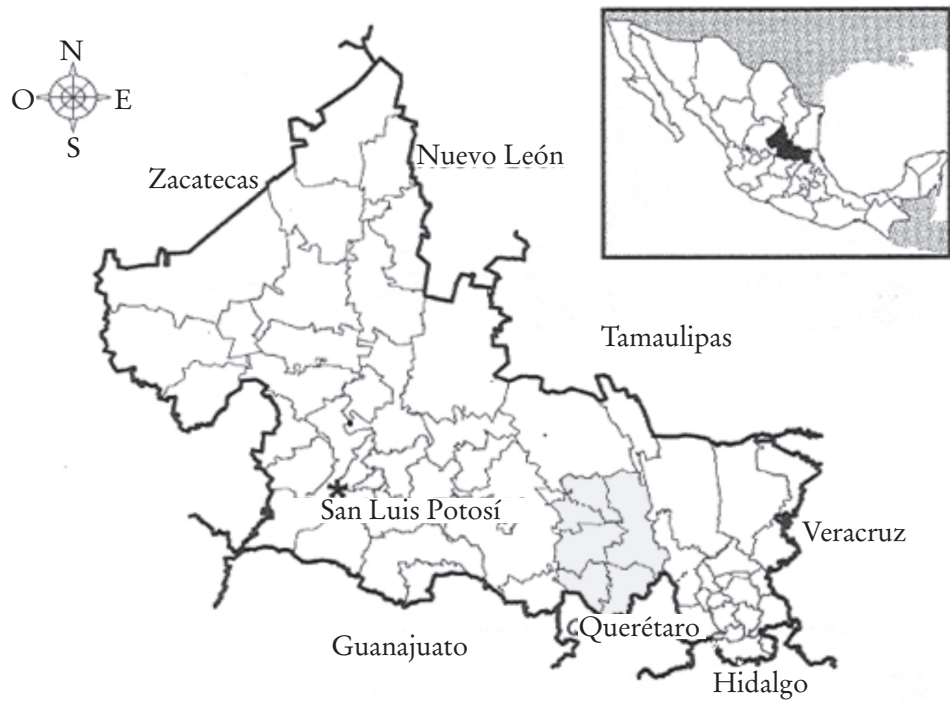

A continuación presento cómo los representantes de las comunidades fueron enfrentando las presiones sobre las tierras y los pueblos desde mediados y hasta la última década del siglo xIx, para entender cómo la defensa del derecho a la tierra era un elemento de cohesión política y étnica que permitió sobrevivir a las comunidades, antecedente necesario 
para comprender el discurso de los pames en el memorial de 1906. Después analizo el amparo pedido por Orozco, como ejemplo del orden legal vigente, y luego describo el "libelo" o memorial. Al final examino el proceso judicial desatado por Arguinzóniz para destacar las penumbras ya mencionadas. La mayor parte de las fuentes utilizadas provienen del fondo civil de la Casa de la Cultura Jurídica de San Luis Potosí (CCJSLP), otras del Archivo General de la Nación de México (AGN).

\section{LA UNIDAD DE LAS COMUNIDADES}

A MEDIADOS DEL SIGLO XIX

Al mediar el siglo xix, dos asuntos impulsaron a los representantes de los pueblos pames a actuar de forma conjunta: por un lado la constante presión sobre sus tierras por las haciendas circundantes, y por el otro la irrupción del orden liberal en el ámbito jurídico y político. ${ }^{25}$ Es posible rastrear en los archivos algunos de sus esfuerzos colectivos, como en 1855, cuando los pueblos de Pinihuán, La Palma, Guayabos y Santa María Acapulco enviaron a Juan Urías y Vicente Martínez como comisionados al Archivo General y Público en la ciudad de México para solicitar "la busca de los títulos de los pueblos expresados". Los comisionados se apoyaron en un Francisco Rosales, a quien incluso le dejaron "unas copias y apuntes antiguos y modernos" sobre las tierras

${ }^{25}$ Desde los comienzos de la vida independiente hubo leyes y propuestas en San Luis Potosí sobre la división y venta de bienes comunales y fundos legales de los pueblos. Escobar y Gutiérrez, "El liberalismo y los pueblos, pp. 260-262. Y el ambiente político de la época era notoriamente contrario a las comunidades y los bienes de comunidad. Fraser, "La política de desamortización en las comunidades indígenas", pp. 615-652. 
pero, según Urías, el señor Rosales cayó en prisión poco después. ${ }^{26}$ Urías suplicó al director del Archivo que se les regresaran los apuntes y copias "para volver con ellos a mi país, a dar cuenta de lo ocurrido contra la persona encargada de hacer la busca de los documentos”. Un año después, en abril otra iniciativa de los indios de La Palma y Gamotes fue por "una compulsación de documentos". ${ }^{27}$ Gamotes no aparece en el documento de 1855, pero también se involucró en la búsqueda de títulos coloniales. El envío de representantes al entonces Archivo Nacional implicó sufragar los gastos requeridos para un viaje de ida y vuelta a la capital, y su estancia por meses en ella. Un esfuerzo grande sin duda, que las comunidades creían valía la pena.

Una década después, en plena intervención francesa, por lo menos dos de las comunidades intentaron de nuevo conseguir amparo legal de sus tierras. En julio de 1865 el gobernador de Pinihuán, Casimiro Tovar, solicitó ante la Junta Protectora de las Clases Menesterosas del gobierno de Maximiliano de Habsburgo que se devolvieran a su comunidad unos terrenos que denunciaba como usurpados por las haciendas colindantes. ${ }^{28}$ Tovar denunció que las haciendas

${ }^{26}$ AGN, T, vol. 3028, exp. 13, f. s. n., Copia simple de escrituras de tierras. Pinihuán, Santa María Acapulco, Guayabos, Estancita, Amoladeras, México, año 1855.

27 Uribe Soto, "La hacienda Estancita”, pp. 249-250.

28 AGN, G, SI, c. 27, exp. 76, Junta Protectora de las Clases Menesterosas, Correspondencia referente a la solicitud elaborada por Casimiro Tovar, gobernador de los indígenas pames del pueblo de Pinihuán del Distrito de Rioverde, sobre devolución de tierras de su comunidad, México, agosto 1865-febrero 1866, ff. 1-4. Para el imperio de Maximiliano y la Junta Protectora de las Clases Menesterosas consúltese Granados GARcíA "Comunidad indígena, imaginario monárquico", pp. 45-73; también 
de Estancita, Amoladeras y Tamasopo habían usurpado una cantidad indefinida de tierras, y aunque el expediente no contiene más detalles del proceso, destaca el argumento jurídico que el gobernador propuso al gabinete imperial: que una vez probada la propiedad de las tierras, por los títulos de fundación, se les devolvieran en posesión "sin que deba admitírseles la excepción que puedan oponer sus propietarios fundada en la prescripción". Ese mismo argumento fue utilizado por el gobernador "del pueblo de indígenas de pames de Gamotes”, Encarnación Hernández, en una solicitud simultánea de devolución de sus tierras incluida en el expediente de Pinihuán..$^{29}$ Hernández señalaba que Estancita, propiedad de Paulo Verástegui, había usurpado tierras de la comunidad y pedía se les devolvieran las tierras "sin que a éste le admita la excepción de prescripción por cuanto a la excepción”.

La Junta Protectora pidió opinión a un letrado que aseguraba haber revisado evidencias similares en otros tres casos. En su argumentación, remitida en enero de 1866, diserta sobre los conceptos de prescripción y excepción invocados por los representantes: prescripción del derecho a poseer una cosa, y excepción legal a esa prescripción. Los "terrenos de los pueblos, puesto que sirven en común a sus vecinos, han sido exceptuados por la ley de la prescripción, y su posee-

PanI, “¿'Verdaderas figuras de Cooper'?” pp. 571-604; PANi, Para mexicanizar el segundo imperio; MARINo, "Ahora que Dios nos ha dado padre", pp. 1353-1410.

${ }_{29}$ Correspondencia referente a la solicitud elaborada por Casimiro Tovar, gobernador de los indígenas pames del pueblo de Pinihuán del Distrito de Rioverde, sobre devolución de tierras de su comunidad; México, agosto 1865 -febrero 1866. AGN, G, SI, c. 27, exp. 76, Junta Protectora de las Clases Menesterosas, ff. 5-15. 
dor en esa virtud jamás podrá defenderse con la excepción que viene de aquéllas". Es decir, que la propiedad de los pueblos sobre esas tierras no había prescrito, que éstas quedaban exceptuadas y sus poseedores actuales, los hacendados, no podían argumentar la prescripción de los derechos de sus antiguos propietarios. ${ }^{30}$ Esta interesante manera de entender los derechos de propiedad daba razón a los representantes de Pinihuán y Gamotes y posibilitaba la restitución de las tierras amparadas por los títulos de las misiones. Pero algo sucedió mientras se deliberaba la resolución, pues otro representante de Pinihuán, de apellido Silva, pidió en octubre de 1865 una audiencia con el emperador ante sus "vehementes temores de que sea desposeída la referida comunidad de los terrenos que por 250 años ha poseído" por una denuncia de terrenos baldíos. "La solicitud de amparo de la expresada comunidad" había pasado de la Junta Protectora al Ministerio de Gobernación, y de éste al de Fomento, lo que causaba el temor de que los esfuerzos fueran en vano: "agotados todos los recursos, únicamente espero su salvación, de la espantosa ruina que la amenaza". No sé si Maximiliano concedió la audiencia ni cómo fue resuelta la solicitud. Las comunidades habían estado peleando en varios ámbitos sus derechos, ${ }^{32}$ pero ante

${ }^{30}$ Correspondencia referente a la solicitud elaborada por Casimiro Tovar, gobernador de los indígenas pames del pueblo de Pinihuán del Distrito de Rioverde, sobre devolución de tierras de su comunidad; México, agosto 1865 -febrero 1866. AGN, G, SI, c. 27, exp. 76, Junta Protectora de las Clases Menesterosas, f. 13.

${ }^{31}$ Correspondencia referente a solicitudes de audiencia con el Emperador, México, 5 de Octubre 1865-27 de Octubre 1865, AGN, G, SI, c. 41, exp. 12, Audiencias, ff. 20, 20v.

${ }^{32}$ Las noticias de esas luchas son dispersas pero se puede decir que fueron una constante. Consúltese Escobar, "Estudio introductorio", p. 81. 
Figura 2

HACIENDAS Y COMUNIDADES EN EL PARTIDO DE HIDALGO, SAN LUIS POTOSÍ, UBICADOS EN LA CARTA GENERAL

DE ESTADO DE SAN LUIS POTOSÍ, DE 1894

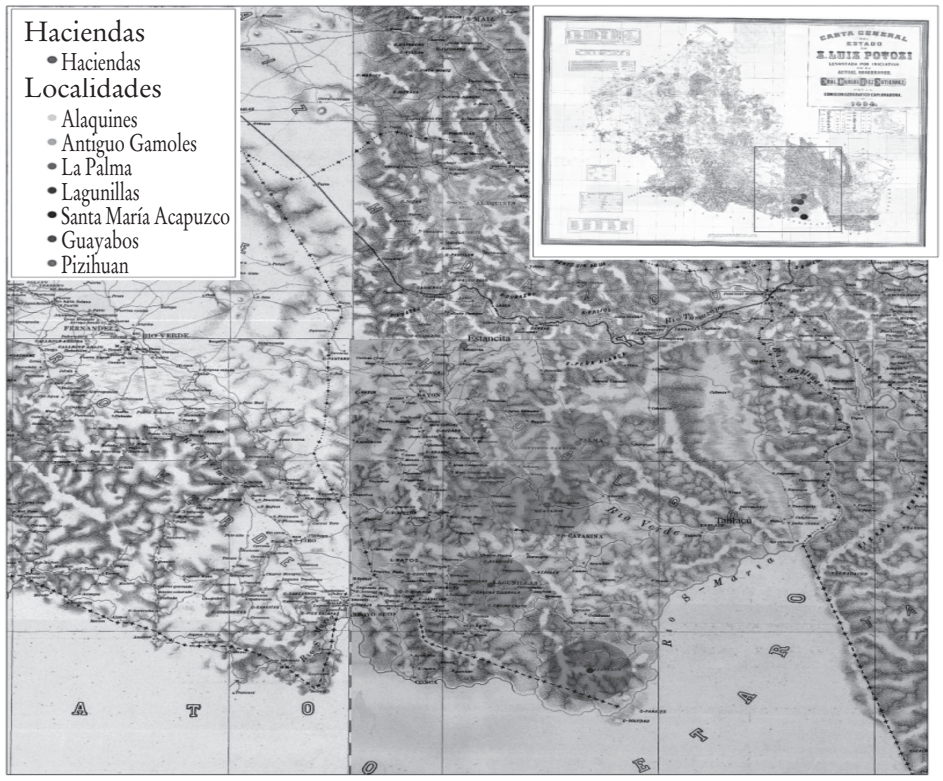

Elaborada por José Alfredo Rangel, con apoyo de Carla Morales. Mapoteca Manuel Orozco y Berza, Colección General, San Luis Potosí, 433-CGE-7242-A.

su falta de éxito buscaron el apoyo del poder político más alto, como lo habían hecho en el periodo colonial, y como lo harían 40 años después. Eran actores buscando incidir en las políticas imperiales mediante un canal privilegiado; por desgracia para ellos, el imperio de Maximiliano fue tan efíme- 
ro como su esperanza de revertir legalmente la posesión que disfrutaban los hacendados.

\section{EL PORFIRIATO}

Para la última década del siglo xix las comunidades del partido de Hidalgo habían defendido sus tierras como habían podido. ${ }^{33}$ Ahora debían deslindar los terrenos que consideraban suyos, negociar con los agentes involucrados en los procesos, como las compañías deslindadoras, y adoptar figuras legales como el condueñazgo. Una de esas compañías estaba registrada como "Rafael García Martínez y socios", y tenía un contrato con la Secretaría de Fomento para realizar los deslindes en el partido de Hidalgo, San Luis Potosí. ${ }^{34}$ Entre sus deslindes estuvo el correspondiente a la hacienda y el pueblo de Tanlacú o Tampot, y resulta muy ilustrativo de los vericuetos en que se transformaban esos deslindes. En enero de 1892 la compañía denunció el predio rústico conocido como Tanlacú, ubicado en la municipalidad de Santa Catarina, partido de Hidalgo.

\footnotetext{
${ }^{33}$ Pueden verse algunos de los conflictos en Escobar, "Tierra y agua en el oriente potosino", pp. 95-97.

${ }^{34}$ La compañía fue autorizada por la Secretaría de Fomento para realizar deslindes en San Luis Potosí, Durango, Sinaloa, Michoacán, Jalisco y Zacatecas. Otra compañía, denominada simplemente Rafael García Martínez, también actuó en Querétaro. Holden, Mexico and the Survey of Public Lands, pp. 30, 31. El contrato para el partido de Hidalgo se firmó en abril de 1888, CCJSLP, JD, C, 211/1891, Juicio de denuncio de terrenos baldíos del predio rústico llamado Guayabos, Alaquines, octubre de 1891, f. 1. Según Escobar, "Estudio introductorio", p. 89, la compañía Rafael García Martínez tenía autorización desde 1889 y por cinco años para deslindes en todo el estado, pero pudo ser una compañía diferente de la aquí mencionada.
} 
Para proceder al deslinde se citó a sus poseedores así como a sus colindantes, representados éstos por el general Manuel González, dueño de la hacienda El Trigo, y por Genaro de la Torre, dueño de San Salvador Tanlacú. ${ }^{35}$ El ingeniero Arturo Maldonado midió las tierras del pueblo de Tanlacú y calculó su superficie en 963 ha o 22 caballerías de tierra "de tercera clase" por ser cerriles o de agostadero y el resto fangosas. En noviembre la compañía pidió al juez que se diera copia certificada del apeo y deslinde a la Secretaría de Fomento. ${ }^{36}$

Al mismo tiempo, en enero de ese mismo año otro apoderado de la compañía, el licenciado Manuel Ruiz, pidió al juez del partido de Alaquines se procediera a deslindar el predio rústico llamado hacienda de Tanlacú, porque le constaba "que los poseedores de dicho predio carecen del título primordial respectivo por el que conste haber salido el terreno del dominio de la Nación". Los dueños del predio eran el senador Antonio Arguinzóniz y Trinidad Rodríguez, esposa de Genaro de la Torre. El terreno colindaba al norte con los pueblos de Guayabos y La Palma, y con la hacienda La Gavia de Manuel Tejera; al norte y oriente con el pueblo de Tanlacú y con la hacienda El Trigo, de Manuel González; al sur con Santa María Acapulco y el río Concá, y al poniente con el pueblo de Lagunillas. ${ }^{37}$

${ }^{35}$ CCJSLP, JD, C, 74/1892, Juicio de deslinde del predio rústico denominado Tanlacú, Alaquines, enero de 1892, f. 1.

${ }^{36}$ CCJSLP, JD, C, 74/1892, Juicio de deslinde del predio rústico denominado Tanlacú, Alaquines, enero de 1892, ff. 6-9.

37 CCJSLP, JD, C, 125/1892, Juicio de deslinde de baldíos en la hacienda de Tanlacú, Alaquines, enero de 1892, f. s. n. La hacienda también era conocida como San Nicolás Tampot. 
Año y medio después, el 25 de octubre de 1893, el senador Antonio Arguinzóniz presentó al juez de Alaquines copia de una certificación que le había otorgado la Secretaría de Fomento. De acuerdo con el documento el senador había exhibido ante la Secretaría "los planos, títulos primordiales y demás documentos relativos al predio rústico denominado Hacienda de Tanlacú”, por lo que le pidió a la instancia federal declarara que en el terreno no había "baldíos, huecos ni demasías”. La base de la petición era un título de composición general de todas las tierras posesión del capitán Juan de Orduña en 1644. Las tierras de la composición incluían las localidades de Santa María Acapulco, San Marcos, San Juan, Guayabos, Tanlacú, el Sauz, valle de Tamasopo y sus potreros, La Palma y Gamotes, entre otras, "una parte de cuyas tierras fueron las que formaron la actual finca de Tanlacú”. La Secretaría afirmó que el gobierno federal siempre había reconocido la validez de los arreglos coloniales, por lo que declaraba que no existían baldíos, huecos, ni demasías en la propiedad de 68122 ha amparadas por los títulos primordiales y por un plano aprobado por la misma Secretaría.

En consecuencia el apoderado de los dueños, licenciado Eduardo Ramírez Adame, solicitó al juez de Alaquines se pusiera en plena posesión del predio a sus representados, pese a la oposición que presentaron sus colindantes: Ramón Mar por el predio de Tanzozob al oriente (en Querétaro), por el sur los pueblos de Tancoyol y Acapulco, representados por sus síndicos, por el occidente Lagunillas, representado por su síndico, por el norte la hacienda El Trigo, de la testamentaria de Manuel González, y el pueblo de Guayabos representado por un vecino o residente, Felipe Castillo. Éste representó también a los dueños del pueblo de Tanlacú, 
lo que de inmediato fue impugnado por Arguinzóniz en la audiencia judicial que tuvo lugar en Alaquines a fines de ese 1893. Según Arguinzóniz, Castillo no podía representar a Tanlacú porque éste no era un pueblo sino un simple rancho que carecía de autoridades municipales, y no los podía representar como congregación o comunidad porque estaba prohibido por la Constitución y por la ley de desamortización. El senador también afirmó que los habitantes de Guayabos arrendaban terrenos a la hacienda de Tanlacú, pero que dejaron de pagar su pensión correspondiente y que eso les hacía creer que tenían derecho a pelear la propiedad; para él solo eran "arrendatarios insurrectos".

Por su parte el síndico de Lagunillas, Lucas Fajardo, se opuso a los linderos que se pretendía reconocer a la hacienda de Tanlacú porque, conforme a sus títulos, Lagunillas nunca había colindado con esa hacienda. El de Guayabos señaló que sus representados tenían desde años pacífica posesión de los terrenos y contra ese hecho no había argumento, pero Arguinzóniz le recordó al juez que el Código Civil decía en su artículo 75 que "es mejor que cualquiera otra la posesión acreditada con título legítimo" ${ }^{38} \mathrm{El}$ juez reconoció el derecho de posesión y propiedad a Arguinzóniz y su codueña. Pero el asunto no quedó resuelto de forma tan sencilla. Felipe Castillo tenía un poder legal de representación de los vecinos propietarios de Tanlacú, registrado ante el alcalde de Rayón en abril de 1892, y un poder registrado ante notario en Rioverde, de mayo de 1892. Así que en diciembre de 1893

38 Para el ideal jurídico de la propiedad privada "perfecta" (es decir, deslindada y titulada), buscado a partir de 1856, consúltese MARINO y ZuleTA, "Una visión del campo”, pp. 438-443. 
denunció, ante el juez de distrito del estado, que Arguinzóniz ocupaba las tierras que pertenecían al pueblo de Tanlacú con pretexto de la posesión de las tierras de su hacienda. En otra denuncia simultánea señalaba que Arguinzóniz incluyó en los límites de la hacienda de Tanlacú a las tierras de Guayabos, que sus poseedores alegaban ser legítimos propietarios pero que se procedía a desalojarlos con violencia.

El apoderado de Arguinzóniz, en cambio, dijo al juez de distrito que las diligencias de posesión fueron realizadas sin violencia. Insistió en que Guayabos y Tanlacú sólo eran ranchos consistentes en de 15 a 20 jacales cada uno, sin autoridades civiles excepto por un encargado de justicia, en que de acuerdo con el proceso de deslinde el río Guayabos marcaba el límite de la hacienda con San Antonio de los Guayabos, y en que sólo se había opuesto el señor Castillo sin mostrar ningún título, porque sus representados eran sencillamente arrendatarios de la hacienda, con una posesión precaria. El expediente termina con la certificación de que ya se había dado posesión a los dueños de Tanlacú. El proceso de deslinde fue impecable y el litigio siguió las formas jurídicas, decidiéndose por los mejores argumentos y los mejores títulos, conforme a las máximas liberales. Los involucrados alegaron derechos y títulos y aparentemente el mejor título venció. La pregunta que debieron hacerse los actores perjudicados fue: ¿qué hizo que el título de composición de 1644 tuviera más valor que los otros títulos? ¿Fue la antigüedad del documento?, ¿o fue la persona que lo presentaba?, ¿o los recursos que manejaba? ${ }^{39}$

\footnotetext{
39 Casos similares ocurrieron con los pueblos de Tampamolón y Tampate. El primero, después de arrendar sus tierras a la familia Santos, las per-
} 
Otro expediente de denuncio de terrenos baldíos ejecutado por la compañía Rafael García Martínez y Socios se refiere a las tierras del pueblo de Guayabos. La operación de deslinde se realizó a finales de 1891 y principios de 1892 ante la presencia de los representantes de Guayabos, los de La Palma y los de Gamotes. El ingeniero Roberto R. Aguirre midió la superficie de los terrenos en 8874 ha $8177 \mathrm{~m}^{3}$, equivalentes a cinco sitios de ganado mayor y dos caballerías 6810 varas cuadradas. ${ }^{40}$ La compañía solicitó que se examinaran los registros de Hacienda para saber si el terreno baldío estaba registrado como propiedad de la nación. Al no estarlo, la compañía procedió a su denuncio. Lo interesante es que al final el expediente señala que la compañía ya negociaba una composición con los poseedores del predio, es decir, los vecinos de Guayabos entendieron que les convenía tratar con el agente que había medido las tierras, antes que la compañía las colocara en el mercado.$^{41}$ Así que les resultó más fácil negociar con la compañía deslindadora que enfrentar a un hacendado, pero su negociación llegó tarde, ya que Arguinzóniz obtuvo su certificado mientras Guayabos tramitaba el suyo.

La misma compañía procedió al deslinde de los terrenos del pueblo Antiguo Gamotes, en enero de 1892. En el pro-

dió en la década de 1890 mediante denuncios y deslindes promovidos por esa familia. Tampate perdió las suyas por "fraudes de las compañías deslindadoras en la misma época". FAJARDO, "La privatización de la tierra", pp. 112, 113.

${ }^{40}$ CCJSLP, JD, C, 211/1891, Juicio de denuncio de terrenos baldíos del predio rústico llamado Guayabos, Alaquines, octubre de 1891, f. 14.

${ }^{41}$ CCJSLP, JD, C, 211/1891, Juicio de denuncio de terrenos baldíos del predio rústico llamado Guayabos, Alaquines, octubre de 1891, f. 30v. 
ceso de deslinde salió a relucir la diferencia entre el lindero reclamado por los pobladores de Gamotes y el pretendido por el administrador de Estancita, hacienda propiedad de Paulo Verástegui. El representante de Gamotes dijo apoyarse en sus títulos de tierras, que mostraría ante autoridad competente, y que Estancita tenía ya de tiempo “dominado" el terreno reclamado. El ingeniero Felipe Gómez del Campo midió la superficie de Gamotes en 5289 ha, 50 áreas, 22 centiáreas, o 3 sitios de ganado mayor 6 fanegas y 18163 varas cuadradas, como terreno de tercera clase. En este deslinde rápidamente salieron a flote los conflictos entre los actores limítrofes y no hubo manera de concluir el asunto. ${ }^{42}$ Conflictos abiertos, tensiones y asuntos sin resolver eran el común denominador, mientras prevalecía la apariencia de que las nuevas leyes daban seguridad y orden.

En cuanto a San Francisco la Palma, fueron los propios vecinos del pueblo los que solicitaron el juicio de apeo y deslinde de sus tierras, en julio de $1891 .{ }^{43}$ Su estrategia fue muy clara desde el principio pues su representante, Juan N. Medina, utilizó el término de "condueños" para evitar la discusión de si eran o no tierras comunales. Medina señaló que sus tierras limitaban al norte con la hacienda de Cárdenas, propiedad del gobernador de San Luis Potosí, Carlos Diez Gutiérrez, por el sur con el pueblo de Guayabos y con el pueblo de Tanlacú, por el oriente con los "pueblos extinguidos" de San Miguel de los Cántaros, Santiago Tampasquin y Santa María Tampalatín, por el poniente con el pueblo de Antiguo Gamotes. Dada la

${ }^{42}$ CCJSLP, JD, C, 232/1892, Juicio de deslinde del predio rústico denominado Antiguo Gamotes, Alaquines, enero de 1892, f. 7.

${ }^{43}$ CCJSLP, JD, C, 87/1891, Juicio de apeo y deslinde de los terrenos de San Francisco la Palma, Alaquines, agosto de 1891, ff. 1-2v. 
inexistencia de varios de esos pueblos, el juez requirió saber quiénes eran los colindantes. Se mencionó al gobernador estatal, al representante del condueñazgo Moctezuma, Gil Moctezuma, además de Antonio Ledesma; Manuel y Francisco Reyes, dueños del terreno llamado Tanque de San Salvador; el general Manuel González; Genaro de la Torre; Felipe Castillo, representante de Guayabos; el pueblo de Gamotes "que es de indígenas”, y Paulo Verástegui por Estancita. ${ }^{44}$

Gran número de indígenas acompañó a Juan N. Medina al comenzar el apeo y deslinde en agosto de ese año. El primer acto se suspendió cuando se llegó a una mojonera que los indígenas aseguraron señalaba el antiguo límite de La Palma con Cárdenas, aunque no estaba el representante de la hacienda. En el siguiente acto surgió la discordancia cuando el representante de la hacienda Estancita, Pedro Martínez, señaló que no eran los límites reales pues "los linderos de Estancita con los terrenos de La Palma son los que hace muchos años se han reconocido [...] según se encuentran demarcados en el plano aprobado por la Secretaría de Fomento". Cuando se procedió al deslinde de las tierras con la parte de Gamotes, en presencia de gran número de los indígenas de este pueblo, otra vez Pedro Martínez protestó en los mismo términos; pidió al juez que ordenara que el plano que se levantaba mostrara claramente los límites argumentados, ya que "en Estancita no hay baldíos huecos ni demasías según consta en la declaración hecha por el Señor Presidente de la República en catorce de febrero de 1890”. ${ }^{45}$

${ }^{44}$ CCJSLP, JD, C, 87/1891, Juicio de apeo y deslinde de los terrenos de San Francisco la Palma, Alaquines, agosto de 1891, ff. 3v., 4-7.

45 CCJSLP, JD, C, 87/1891, Juicio de apeo y deslinde de los terrenos de San Francisco la Palma, Alaquines, agosto de 1891, ff. 12-13v. 
Entonces, el 21 de septiembre de 1891, el proceso dio un giro inesperado, cuando Modesto Gómez, quien dijo ser "apoderado judicial de la comunidad de San Francisco de la Palma”, presentó un escrito al juez de distrito. En él se dijo "convencido" de que en febrero de 1890 la Secretaría de Fomento declaró que "la Federación no tenía derecho a predio alguno baldío por no haberlos, así como tampoco a huecos y demasías dentro de los límites de las referidas haciendas en los términos y condiciones que actualmente los poseen sus respectivos dueños". conforme la solicitud y documentos presentados por Paulo Verástegui. Así que la comunidad que representaba:

Carece de derecho legítimo para reivindicar cualquiera porción de terreno dentro de los linderos antes mencionados de las referidas haciendas. Que aun cuando esto no fuera cierto, como efectivamente lo es, estoy igualmente convencido de que tratándose de bienes raíces de común repartimiento, no toca a la competencia de las autoridades federales, sino exclusivamente a la del estado de San Luis Potosí dirimir todo género de controversias judiciales o del orden administrativo, que con los referidos bienes se relacionen, por inferirse así recta y lógicamente de la Circular del Presidente de la República, expedida por la Secretaría de Gobernación en 12 de mayo del año próximo pasado de $1890 .{ }^{46}$

Después de ver el esfuerzo hecho por el anterior representante de La Palma este argumento era sorprendente. ${ }^{47}$

${ }^{46}$ CCJSLP, JD, C, 87/1891, Juicio de apeo y deslinde de los terrenos de San Francisco la Palma, Alaquines, agosto de 1891, ff. 17, 17v.

$47 \mathrm{El}$ argumento también es sorprendente desde el punto de vista histo- 
Varias cosas se pueden apuntar al respecto. Primero, que la inesperada maniobra de retroceso posiblemente indica las luchas internas en la comunidad entre diferentes perspectivas $\mathrm{y}$ formas de entender los procesos que afectaban al pueblo. Gómez pudo ser parte de los grupos de arrendatarios que se beneficiaban de tener buenas relaciones con los grandes propietarios, aun a costa de la pérdida de las tierras de los pueblos. Igualmente pudieron existir presiones de los dueños de Cárdenas y Estancita contra los líderes del pueblo para revertir el proceso. El nuevo apoderado se desistió en nombre de sus representados de las gestiones emprendidas para reclamar lo que "equivocadamente creí tener derecho de hacer valer". Como respaldo de sus afirmaciones presentó un poder otorgado por los indios de La Palma ante el juez de primera instancia del partido de Hidalgo, el 12 de agosto de 1891.

Pero su "convencimiento" de que las haciendas colindantes no poseían demasías a costa de su comunidad era una aseveración que legalmente sólo podía dar un ingeniero agrimensor, y la única medida a la vista era la que respaldaba el documento presentado por Verástegui. Gómez también estaba convencido de que la comunidad no tenía razón ni derecho de pelear tierras, asumiendo el mismo punto de vista de los hacendados. Además aseguró que La Palma tenía bienes comunales, lo que los colocaba fuera de la ley, un verdadero suicidio legal. Jurídicamente hasta un documento de propiedad expedido por el presidente podía ser peleado en un jui-

riográfico, ya que si algo caracterizó a los actores sociales de la época fue la búsqueda de formas de aprovechar la legislación liberal en su beneficio para conservar, recuperar o aumentar sus propiedades. Fajardo Peña, "La privatización de la tierra", p. 100. 
cio si había mejor derecho de los opositores (como se decía en la época), pero si los reclamantes se retiraban el proceso se cerraba. Así que la opinión subjetiva de Gómez daba al traste con un juicio administrativo y con una lucha de años. Ante el beneficioso cambio, Paulo Verástegui pidió una copia certificada del desistimiento el 28 de septiembre. El expediente termina con Modesto Gómez solicitando al juez los títulos de La Palma; obtuvo en devolución "un testimonio de la escritura de composición de las tierras de la Villa de San Francisco La Palma del partido de Rioverde, estado de San Luis Potosí, expedido en México el dos de abril de mil ochocientos cincuenta y seis". ${ }^{48} \mathrm{El}$ saldo de esa década fue negativo para las comunidades, mientras el orden jurídico y político aparentaba normalidad. En ese contexto Wistano Orozco llegó a la zona al comenzar el siglo xx como experto en asuntos de tierras, y como señalé al inicio, su éxito llamó la atención de las comunidades, que lo convencieron de tomar sus casos.

\section{EL AMPARO SOLICITADO \\ POR WISTANO LUIS OROZCO}

El 18 de febrero de 1907 el senador por Querétaro, Antonio Arguinzóniz, por medio de su apoderado general, Pablo Dueñas, denunció ante el juez de primera instancia de Alaquines, San Luis Potosí, por difamación o calumnia, a Wistano L. Orozco. ${ }^{49}$ Lo acusaba de ser el instigador y el autor

${ }^{48}$ CCJSLP, JD, C, 87/1891, Juicio de apeo y deslinde de los terrenos de San Francisco La Palma, Alaquines, agosto de 1891, ff. 19-21v.

${ }^{49}$ CCJSLP, JD, A, núm. 51, Juicio de amparo solicitado por el Lic. Wistano Luis Orozco contra el juez de primera instancia de Alaquines, por orden de aprehensión, México, marzo de 1907. 
literal de un ocurso o libelo con una serie de calumnias en contra suya, con el pretexto de la defensa de las tierras de las comunidades de Lagunillas, Gamotes, Santa María Acapulco, Guayabos y La Palma. El ocurso contenía las quejas por los despojos de tierras y los maltratos a los que se decían sometidos, donde Arguinzóniz era "uno de los principales directores de los atentados que han sufrido sus derechos”. Dueñas aseguraba que ese escrito tenía por objeto presentar a su poderdante "bajo el peor aspecto posible ante el Señor Secretario de Fomento y ante el Señor Presidente de la República". ${ }^{50}$ Se le presentaba como alguien "sin escrúpulos, ávido de enriquecerse con perjuicio de otros y que no repara los medios para llegar al fin que se propone". ${ }^{11}$ Tales imputaciones lo exponían al "desprecio de las autoridades federales", por lo que "en defensa de su reputación y su dignidad tan injustamente ultrajadas" el apoderado de Arguinzóniz presentaba la denuncia por difamación contra todos los que suscribieron el ocurso, y contra quienes fueran apareciendo como cómplices o coautores del mismo en el curso de las averiguaciones. ${ }^{52}$

50 Dueñas obtuvo el poder de representación de Arguinzóniz el 26 de octubre de 1906, por lo que probablemente el senador conoció el escrito de Orozco apenas hubo llegado a la Secretaría de Fomento, CCJSLP, JD, A, núm. 51, Juicio de amparo solicitado por el Lic. Wistano Luis Orozco contra el juez de primera instancia de Alaquines, por orden de aprehensión, México, marzo de 1907, f. 29.

${ }^{51}$ CCJSLP, JD, A, núm. 51, Juicio de amparo solicitado por el Lic. Wistano Luis Orozco contra el juez de primera instancia de Alaquines, por orden de aprehensión, México, marzo de 1907, f. 59.

${ }^{52}$ CCJSLP, JD, A, núm. 51, Juicio de amparo solicitado por el Lic. Wistano Luis Orozco contra el juez de primera instancia de Alaquines, por orden de aprehensión, México, marzo de 1907, ff. 21, 21v. 
Denuncias y litigios relacionados con la libertad de expresión y los derechos individuales eran normales en el porfiriato, ya que difamar, injuriar o calumniar estaban tipificados como delitos contra el honor. ${ }^{53}$ Así que el juez de primera instancia, Luis G. Gómez, le dio la razón al terrateniente y ordenó el arresto de Orozco el 25 de febrero, por lo que éste tramitó un amparo ante el juez de distrito, Tomás Ortiz, el 7 de marzo de 1907. Como Orozco estaba en la ciudad de México, redactó su solicitud el 4 de marzo y la envió por correo a Nicolás Carreño, para que fuera su representante ante el juez de Alaquines. En el amparo Orozco señaló al juez de distrito que los "cabezas de familia" de las comunidades le encomendaron su defensa y el escrito dirigido al presidente Porfirio Díaz. Aparte de las quejas, pedían al presidente que ordenara a la Secretaría de Fomento nombrara un ingeniero para que midiera las tierras que reclamaban conforme a sus títulos, "y una vez hecho el reconocimiento y deslinde, declarar que esas tierras son de la propiedad de las comunidades reclamantes". Wistano aceptaba haber escrito el documento: "La solicitud se hizo bajo mi dirección, y yo redacté el memorial respectivo". ${ }^{54}$ Relató que una muchedumbre se había presentado ante él, y escuchó a los que se decían los representantes mientras tomaba "apuntes precisos", y luego los rectificó y depuró "oyendo a los interesados cuantas veces fue necesario". Cuando terminó de redactar el documento lo leyó en voz alta dos veces a la multitud, y

${ }^{33}$ Consúltese Serna, "Casos que motivaban la interposición del amparo", pp. 3-26.

${ }^{54}$ CCJSLP, JD, A, núm. 51, Juicio de amparo solicitado por el Lic. Wistano Luis Orozco contra el juez de primera instancia de Alaquines, por orden de aprehensión, México, marzo de 1907, f. 1. 
entonces procedieron a firmarlo en grupos de comunidades. La firma duró un día completo y, como no se trataba de un instrumento legal de transmisión de derechos o de establecimiento de obligaciones, Orozco no se interesó en verificar sus identidades, pero aseguró haberles dejado el documento para que los interesados lo confirmaran y le sacaran copia si lo consideraban necesario. ${ }^{55}$ Orozco tuvo guardado en su poder el memorial hasta el 30 de septiembre de 1906, cuando se decidió enviarlo a su destinatario. Había meditado las posibles consecuencias que tendría una solicitud de esa naturaleza: "para darme tiempo de reflexionar si era procedente nuestra petición conforme a los preceptos de la Real Instrucción de 15 de octubre de 1754 y demás leyes relativas a terrenos baldíos". ${ }^{56}$

Desde el punto de vista de Orozco, el asunto no había salido de la esfera administrativa porque todavía no se recibía una respuesta a su solicitud, y no se habían hecho citaciones judiciales para los deslindes. En ese lapso Arguinzóniz había obtenido una copia certificada de la solicitud, "sin ser parte todavía de ese negocio, pasando por sobre el señor Presidente de la República que lo tiene bajo su privativo conocimiento, y por sobre el fuero y jurisdicción de los jueces de esta capital”, y con base en esa copia había presentado la demanda por difamación o calumnia en el juzgado de primera instancia de Alaquines. En otras palabras era claro que

${ }^{55}$ CCJSLP, JD, A, núm. 51, Juicio de amparo solicitado por el Lic. Wistano Luis Orozco contra el juez de primera instancia de Alaquines, por orden de aprehensión, México, marzo de 1907, ff. 13-14v.

${ }^{56}$ CCJSLP, JD, A, núm. 51, Juicio de amparo solicitado por el Lic. Wistano Luis Orozco contra el juez de primera instancia de Alaquines, por orden de aprehensión, México, marzo de 1907, f. 2. 
el senador tenía acceso privilegiado a información que le podía perjudicar, como el memorial. Ese rasgo de la política mexicana nada tenía que ver con el precepto liberal de igualdad ante la ley, sino con la indefinición misma de lo que era posible y no para los poderosos en el nuevo orden. Acceder de forma privilegiada a la información importante permitía establecer estrategias de defensa muy efectivas, mientras los otros actores debían conformarse con los tiempos y procesos marcados por la ley. ${ }^{57}$

Ante la orden girada en su contra, Orozco pedía el amparo federal al considerar violadas las garantías individuales en su persona, conforme a los artículos 14 y 16 de la Constitución federal. Su argumento se basaba en el hecho de que si el delito del que se le acusaba era difamación o calumnia, era por "comunicar dolosamente a una o más personas un hecho que podía causar deshonra, perjuicio o descrédito al difamado o calumniado", así que mientras no se comunicara el hecho no habría delito. ${ }^{58}$ Tampoco había la intención dolosa que marcaba el código penal de San Luis Potosí como requisito, y si no se probaba tal intención, no había delito que perseguir. Además, no se podía acusar de dolo cuando en una reclamación civil los hechos alegados eran el fundamento de la acción ejercida, porque de lo contrario toda reclamación

57 Paolo Riguzzi señala que el acceso de los grupos de interés a información privilegiada era uno de los elementos que obstaculizaban el establecimiento de formas económicas modernas en México en la segunda mitad del siglo XIX, pero la observación vale también para entender los problemas en torno a la creación de un libre mercado de tierras (cara aspiración liberal), así como los problemas para aplicar la justicia entre ciudadanos en teoría iguales. Riguzzi, “Libre cambio y libertad económica”, pp. 287-291.

${ }_{58}$ Para los contextos de la época consúltese Serna, "Casos que motivaban la interposición del amparo", p. 18. 
por hechos graves (robo, fraude, despojo, etc.) sería imposible "y se desquiciaría el orden social". ${ }^{59}$

Aparte de que el supuesto "delito" habría sido cometido en la capital del país y no en Alaquines, Orozco señalaba que mientras el presidente de la República, como primer magistrado, no diese trámite a la petición presentada, no podía el juez entremeterse ni Arguinzóniz decirse afectado. Éste había acusado a Wistano L. Orozco de haber instigado a los indios a involucrarse en el asunto, y de escribir el ocurso e inventar todo su contenido. Si bien es posible que Orozco lo inventara, hacerlo de forma verosímil resultaba bastante difícil; además, una falsificación hubiera puesto en peligro su carrera legal y, obviamente, su libertad. Claro que también es posible que los indígenas inventaran todo, como argumentó el propio Orozco en su defensa:

Por los mismos términos y naturaleza del escrito de que se queja don Antonio Arguinzóniz, se comprende que no puedo yo ser responsable de la narración de los hechos; sino únicamente de su aplicación legal como Abogado. - Yo no presencié el despojo de Guayabos, ni puede haber dicho esto en su queja el señor Arguinzóniz; así es que dejé la palabra a los reclamantes, y bajo el informe de 300 hombres que se quejan al señor Presidente de diversos despojos, formulé yo su Memorial, que bajo el supuesto de ser ciertos los hechos alegados, es enteramente justificado.

No es natural que tantos hombres me hayan engañado; pero si así lo hicieron, ellos serán los responsables de su infor-

${ }^{59}$ CCJSLP, JD, A, núm. 51, Juicio de amparo solicitado por el Lic. Wistano Luis Orozco contra el juez de primera instancia de Alaquines, por orden de aprehensión, México, marzo de 1907, f. 2v. 
me sobre los hechos; pero a mí, solo se me puede reclamar la aplicación del derecho. ¡Dónde iríamos a dar los abogados, si tuviéramos que responder de los hechos alegados por nuestros clientes! ${ }^{60}$

En todo caso, señaló, las acusaciones contenidas en el memorial implicaban más bien "a los jueces y autoridades que ayudaron en ese asunto a don Antonio Arguinzóniz. Los encarcelamientos, los secuestros de semillas, las multas, son cosas que, si las pidió don Antonio, no pudo ejecutarlas él mismo, y no le son imputables a él, sino a las autoridades que decretaron y ejecutaron esas cosas”. El alegato de Orozco iba tras la fachada jurídica para resaltar el tipo de acciones y aseveraciones contrarias a la letra de la ley, para así obtener el amparo federal.

Poco después el juez de Alaquines aceptó que el supuesto delito se había efectuado en la capital mexicana y no en su jurisdicción, por lo que no le correspondía decidir sobre el mismo; sin embargo, siguió el proceso de investigación porque el representante de Arguinzóniz apeló su decisión y pidió que entre tanto siguiera el proceso. En ese lapso introdujo la acusación de falsificación de documentos y una nueva orden de aprehensión contra Orozco, porque en el proceso seguido en su juzgado algunos de los firmantes y de los sujetos mencionados se retractaron de lo señalado en el escrito, ${ }^{61}$

${ }^{60}$ CCJSLP, JD, A, núm. 51, Juicio de amparo solicitado por el Lic. Wistano Luis Orozco contra el juez de primera instancia de Alaquines, por orden de aprehensión, México, marzo de 1907, ff. 3, 3v.

${ }^{61}$ CCJSLP, JD, A, núm. 51, Juicio de amparo solicitado por el Lic. Wistano Luis Orozco contra el juez de primera instancia de Alaquines, por orden de aprehensión, México, marzo de 1907, ff. 12-17v. 
como Vicente Salazar, “agente de negocios judiciales” en Alaquines, cuya firma aparecía en el memorial como "apoderado general de las comunidades”. Salazar negó haber firmado el ocurso en ese sentido y dijo que lo había rubricado porque se lo pidió Orozco; además, como él no era apoderado general de ninguna comunidad, sino que tiempo atrás lo había sido de La Palma, Orozco lo convenció de firmar como testigo ocular de los hechos relatados por la gente del pueblo, y para ello sólo le leyó la parte relativa a La Palma. Así que "por consecuencia tal ante-firma, en que ahora se le quiere conferir una representación e intervención que no ha tenido, la desconoce como falsa". ${ }^{62}$

Orozco respondió al juez de distrito que tales retractaciones no invalidaban el memorial ni indicaban la falsificación, porque en teoría el juez de primera instancia no había visto el documento original, y por tanto no podía proceder con diligencias de reconocimiento o cotejo de firmas, así que esa nueva acusación carecía de fundamento legal. Por otro lado, como el alegato era por tierras reclamadas como "bienes pro indiviso" no hacían falta las firmas de todos los interesados, sino sólo de los representantes. ${ }^{63}$ Orozco recurrió también a un argumento jurídico político: el memorial enviado al presidente Díaz era un "documento de Estado, que sólo puede obrar en los archivos de Gabinete”, por lo cual Arguinzóniz como particular no podía

${ }^{62}$ CCJSLP, JD, A, núm. 51, Juicio de amparo solicitado por el Lic. Wistano Luis Orozco contra el juez de primera instancia de Alaquines, por orden de aprehensión, México, marzo de 1907, ff. 54, 54v.

${ }^{63}$ CCJSLP, JD, A, núm. 51, Juicio de amparo solicitado por el Lic. Wistano Luis Orozco contra el juez de primera instancia de Alaquines, por orden de aprehensión, México, marzo de 1907, f. 15v. 
usarlo, hasta que se creara un expediente de deslinde donde se le admitiera como parte interesada; así que en caso de que un incidente se suscitara por el proceso sería un juez federal quien conociera del asunto, no uno local. ${ }^{64}$

Si el memorial era una solicitud de deslinde de tierras "pro indiviso" el asunto tenía carácter administrativo y no judicial. Así que Orozco acusó otra vez al juez de Alaquines de violar las garantías individuales en su contra aunque "sin formar nuevo incidente de suspensión”; sólo pedía que el juez de distrito suspendiera los actos reclamados en una sola sentencia. Mientras resolvía el amparo, el juez de distrito recibió copia del polémico memorial tal y como fue enviado por Orozco a Díaz. Procedo con el documento.

\section{EL MEMORIAL DE LAS COMUNIDADES}

Lo primero que llama la atención del memorial es el uso del término comunidad que utilizan los representantes. A 90 años de la desaparición del régimen colonial el término era de uso acostumbrado entre los líderes indígenas. El término significa el conjunto de individuos que reconocían su residencia en una localidad y que participaban de ciertos valores comunes, y que coincidían en la necesidad de actuar de forma colectiva frente a situaciones que consideraban opresivas y hasta humillantes. El reclamo por las tierras, las perdidas y las que estaban en riesgo de perderse, condensaba los reclamos de cada grupo. Esto no significaba que todos los vecinos

${ }^{64}$ CCJSLP, JD, A, núm. 51, Juicio de amparo solicitado por el Lic. Wistano Luis Orozco contra el juez de primera instancia de Alaquines, por orden de aprehensión, México, marzo de 1907, f. 16v. 
de una localidad estuviesen en total acuerdo sobre las formas de entender las cosas, los medios en que podían actuar políticamente y sus necesidades colectivas. Las divergencias estaban presentes, como hemos visto, pero aquí me interesa identificar la postura de defensa de los líderes de los pueblos porque indican acuerdos políticos en el interior y entre los mismos líderes.

La primera comunidad mencionada fue Santa María Acapulco, localidad situada en el extremo sur de San Luis Potosí, casi en los límites con el estado de Querétaro y fundada en el siglo XVII como visita de la misión franciscana de Tanlacú. ${ }^{65}$ Citaron en principio una merced de tierras de 1696 de una concesión "perfecta y bien definida" con sus colindancias: "al norte concesión al pueblo de Lagunillas; al oriente, concesión real a la estación de Tampot, hoy Tanlacut, al sur concesión al pueblo de San José del Sáuz; y al poniente, con la concesión de Concá y Lagunillas". ${ }^{66}$ Los firmantes señalaron que las tierras de la merced real habían sido "cercenadas" en tres sitios de ganado mayor y menor ${ }^{67}$ por Antonio Arguinzóniz y por el general Rafael Olvera ${ }^{68}$ ("hombre poderoso en la Sierra de Jalpan") y su hermano y heredero Gregorio. Tales pérdidas habían ocurrido en dife-

${ }^{65}$ Rangel Silva, "Pames, estancieros”, pp. 246-248.

${ }^{66}$ CCJSLP, JD, A, núm. 51, Juicio de amparo solicitado por el Lic. Wistano Luis Orozco contra el juez de primera instancia de Alaquines, por orden de aprehensión, México, marzo de 1907.

${ }^{67}$ Un sitio de ganado mayor equivalía a 1755 ha, un sitio de ganado menor a 780 hectáreas, aproximadamente, Holden, Mexico and the Survey of Public Lands, p. xv.

${ }^{68}$ Rafael Olvera era un rico propietario en la región, y durante algún tiempo socio del exgobernador Carlos Diez Gutiérrez. Consúltese RaNGEL Silva, "Transformaciones en la propiedad agraria”, p. 87. 
rentes ocasiones, y aunque decían haberse apoyado con abogados, éstos habían desistido después de cierto tiempo. Así que, asesorados por Wistano L. Orozco, los representantes de Acapulco habían promovido un juicio de apeo y deslinde "preparatorio de una acción reivindicatoria de dominio", es decir, usaron los recursos legales y el lenguaje jurídico en boga, argumentando que sus tierras eran de propiedad particular aunque indivisa. Sin embargo, en julio de 1905 el Supremo Tribunal de Justicia de San Luis Potosí declaró en segunda instancia

[...] que las comunidades de indígenas han desaparecido legalmente y no pueden constituir un apoderado que las represente, y que en cuanto a sus bienes actuales, como agrupaciones de hecho sólo pueden ser representadas por los síndicos de los ayuntamientos. ${ }^{69}$

Esa decisión judicial los privaba de ejercer sus derechos de propiedad aun cuando habían ajustado sus reclamos a los términos liberales en boga. El problema era que se presentaban como comunidad cuando las leyes ya no reconocían el concepto, resolución que, decían, dejaba a las comunidades indígenas "a merced de la codicia y rapacidad de sus vecinos opulentos”. Pero la pérdida del derecho de representación jurídica estaba acompañada de otros problemas que afectaban sus derechos; por ejemplo, dijeron que en 1905 habían elegido sus regidores y síndicos para el ayuntamiento del municipio de Santa Catarina, al que pertenecían, pero "la

${ }^{69}$ CCJSLP, JD, A, núm. 51, Juicio de amparo solicitado por el Lic. Wistano Luis Orozco contra el juez de primera instancia de Alaquines, por orden de aprehensión, México, marzo de 1907. 
legislatura del estado dio un decreto declarando nula nuestra elección”. Según su narración el jefe político del partido de Hidalgo, Mariano Zúñiga, se hizo acompañar de gente armada para deshacer la elección, ${ }^{70}$ y ordenó otras para nombrar síndicos y regidores entre los sirvientes de Arguinzóniz, además de obligar a los varones del pueblo que mostraron alguna resistencia a trabajar un mes en la obra material de la iglesia de Santa Catarina; Zúñiga también multó al juez auxiliar de Acapulco, es decir, la única autoridad local que reconocía. ${ }^{71}$ Según el memorial el gobernador del estado, José María Espinosa, había cancelado las penas laborales y económicas a una solicitud expresa de Orozco. ${ }^{72}$ Vemos así descrita la lucha por el poder local entre varias facciones en Santa María Acapulco: una que parece mayoritaria y compuesta por residentes del pueblo, antiguas autoridades indias y apoyada en el juez local, y otra compuesta de sirvientes de las haciendas, en especial de la de Arguinzóniz, y probablemente minoritaria hasta entonces. Capataces, propietarios y autoridades locales y regionales también intervenían en las disputas pero de forma soterrada, pues cuando lo hacían abiertamente rompían los límites acostumbrados por los diferentes bandos.

70 Ankerson también señaló a Zúñiga como nefasto y arbitrario. ANKerson, El caudillo agrarista, p. 21.

${ }^{71}$ Antonio Arguinzóniz también intervino al comienzo de los pleitos con los condueños de los terrenos de los Moctezuma, que denunció como baldíos. Gutiérrez, "El condueñazgo de los Moctezuma”, p. 246.

${ }^{72}$ CCJSLP, JD, A, núm. 51, Juicio de amparo solicitado por el Lic. Wistano Luis Orozco contra el juez de primera instancia de Alaquines, por orden de aprehensión, México, marzo de 1907, ff. 22v., 23. 
A pesar de la presión interna y externa, los representantes de Santa María Acapulco requirieron a la justicia federal que los amparara contra la sentencia de la Corte estatal. Sin embargo, el juez de distrito de San Luis Potosí, Tomás Ortiz, se había negado a dar entrada a la solicitud de amparo. Para los indígenas, entre las razones de Ortiz para rechazar la solicitud de amparo estaba "su criterio de exterminio contra la raza indígena”, porque el juez era un "funesto personaje que hizo una gira devoradora de más de dos años, haciendo pedazos a las comunidades de las Huasteca, como visitador oficial de aquella zona". ${ }^{73}$ Ante tan desalentador panorama, reclamaban al presidente Díaz: “Así pues, desde el Juez de Distrito y la Legislatura del Estado hasta los síndicos municipales de Santa Catarina, no tenemos en esta Entidad federativa sino elementos de muerte con quienes tropezar en nuestra vida civil”.

Enseguida tocó el turno a San Antonio de los Guayabos, ubicado unos cuantos kilómetros al norte de S. M. Acapulco y también fundado en el siglo XVII como misión franciscana. ${ }^{74}$ Sus representantes igualmente citaron una merced de tierras supuestamente emitida por el virrey Francisco de Valenzuela y Venegas en 1696 para un terreno de ocho leguas de circuito. ${ }^{75}$ Probablemente ese documento fuera un títu-

${ }^{73}$ CCJSLP, JD, A, núm. 51, Juicio de amparo solicitado por el Lic. Wistano Luis Orozco contra el juez de primera instancia de Alaquines, por orden de aprehensión, México, marzo de 1907, ff. 23, $23 \mathrm{v}$.

${ }^{74}$ Rangel Silva, "Pames, estancieros", pp. 246-248.

${ }^{75}$ En realidad Valenzuela y Venegas era oidor de la Real Audiencia y "Real Chancillería", y fue "juez privativo de composiciones de tierras y aguas ralelias o realengas" en ese año, AGN, $T$, vol. 1860, exp. 5, Títulos de las tierras del pueblo de San Felipe de los Gamotes, México, año 1696, ff. 99-105. 
lo de composición de tierras, pero para todo propósito de defensa de sus tierras era igualmente útil y válido. De acuerdo con los representantes, "Nosotros y nuestros causantes habíamos disfrutado pacíficamente nuestras tierras, hasta el año de mil ochocientos noventa y siete, en cuyo tiempo el Sr. Senador D. Antonio Arguinzóniz nos despojó de toda nuestra propiedad". ${ }^{76}$ Ese año la Secretaría de Fomento le otorgó al senador Arguinzóniz "una declaración” oficial que le daba posesión solemne de las tierras de Tampot, declarando además que no tenía baldíos, huecos ni demasías; por supuesto que el reconocimiento incluía las tierras que Guayabos consideraba suyas. Después Arguinzóniz pidió en jurisdicción voluntaria que el juez de distrito le diera posesión de las tierras amparadas por la declaración de la Secretaría de Fomento, consumando así la maniobra. Ya relaté lo acontecido en la década anterior, por lo que podemos ver la intermitente lucha entre Guayabos y Arguinzóniz. Éste utilizó gente armada para amenazar a los que se opusieron al despojo, y mandó encerrar algunos de los residentes, ya fuera en sus propios domicilios o en la cárcel de Alaquines. ${ }^{77}$ Otros fueron obligados a "expatriarse" de Guayabos. El recurso de fuerza no era raro en la zona; otro gran propietario, Antonio Espinoza, usó la fuerza armada contra pequeños propietarios colindantes de su hacienda Angostura. ${ }^{78}$

\footnotetext{
76 CCJSLP, JD, A, núm. 51, Juicio de amparo solicitado por el Lic. Wistano Luis Orozco contra el juez de primera instancia de Alaquines, por orden de aprehensión, México, marzo de 1907, ff. 23v, 24.

77 CCJSLP, JD, A, núm. 51, Juicio de amparo solicitado por el Lic. Wistano Luis Orozco contra el juez de primera instancia de Alaquines, por orden de aprehensión, México, marzo de 1907, ff. 24, 24v.

78 Para el caso de Angostura véase Ankerson, El candillo agrarista, p. 18.
} 
Pero el senador por Querétaro también permitió que sus ayudantes impusieran multas por 150 pesos a quienes supongo eran los líderes comunales, antiguos jueces locales y cualquiera que tuviera algún peso dentro del pequeño pueblo y sus ranchos anexos. Si bien los detalles dramáticos de las prisiones, los despojos y las expulsiones debieron exagerarse para conmover al destinatario (Díaz), le permiten al historiador tener una idea de las resistencias de los pobladores de Guayabos. Por otro lado, para Arguinzóniz el asunto era simplemente hacer valer sus derechos de propiedad, respaldados en un título perfecto expedido por la autoridad correspondiente. Seguro que le exasperó la tozudez de los residentes de los pueblos, y sin duda debió haber excesos en ambos lados, pero no se debe obviar que la ley, la fuerza armada y la estructura judicial estaban a favor del flamante propietario. Un detalle nos deja ver el carácter impetuoso del propietario: "El 16 de julio del corriente año amenazó ese hombre con un lance de armas a nuestro abogado Lic. W. L. Orozco, en los bajos del hotel San Carlos, ciudad de México, por el solo hecho de haber aceptado nuestro poder para reclamar nuestros derechos" ${ }^{79}$

Más allá de las anécdotas, la desesperación de los representantes los llevó a señalar que, en su opinión, era inútil pedir se les hiciera justicia en el estado de San Luis Potosí; por eso se animaron a apelar a la máxima autoridad de la nación. Era una medida desesperada y al mismo tiempo era un movimiento lógico dentro de la cultura política de la época, pues

79 CCJSLP, JD, A, núm. 51, Juicio de amparo solicitado por el Lic. Wistano Luis Orozco contra el juez de primera instancia de Alaquines, por orden de aprehensión, México, marzo de 1907, ff. 25, 25v. 
no se salían de los cauces institucionales, sólo ampliaron el horizonte de los posibles canales de negociación.

El memorial continuó con la parte correspondiente a Gamotes, otra antigua misión franciscana conocida en tiempos coloniales como San Felipe de los Gamotes. Sus representantes citaron primero una merced real del mismo año 1696 por "un terreno de cuatro leguas en cuadro más que menos". Es probable que la composición de tierras de ese 1696 (ya mencionado para el caso de Guayabos) incluyera a varias de las misiones y sus visitas, lo que las ayudó a defender su propiedad frente a los estancieros de la época. Los pueblos de indios no estaban obligados a componer sus tierras y títulos, pero de cualquier manera aprovecharon la oportunidad abierta por la corona. ${ }^{80} \mathrm{El}$ memorial señala que los dueños de la hacienda Estancita arrendaban la parte norte de las tierras, y "bajo ese pretexto avanzaron hasta apoderarse de la mayor parte de nuestras posesiones, usurpaciones que calculamos en tres sitios de ganado mayor" ${ }^{81}$ Era una práctica común que hacendados y vecinos de las localidades arrendaran tierras a los pueblos y las comunidades, que así obtenían ingresos para diferentes objetivos como el pago de contribuciones. Pero en la segunda mitad del siglo XIX esos arrendamientos fueron utilizados para justificar denuncios de tierras por quienes se decían poseedores. Recientes investigaciones

\footnotetext{
${ }^{80}$ Hasta 1707 la legislación de Indias no obligaba a los indios a componer sus títulos y propiedades, Ruiz Medrano, “El espejo y su reflejo”, p. 175. 81 CCJSLP, JD, A, núm. 51, Juicio de amparo solicitado por el Lic. Wistano Luis Orozco contra el juez de primera instancia de Alaquines, por orden de aprehensión, México, marzo de 1907, ff. 25, 25v. Los dueños de Estancita eran de la familia Verástegui. Uribe Soto, "La hacienda Estancita”, pp. 244-247.
} 
han mostrado que esa estrategia surgió con la aplicación de las leyes liberales, que obligaban a los arrendatarios a denunciar las tierras que poseían, ${ }^{82}$ es decir, que fue resultado de las condiciones socioeconómicas en el agro, combinadas con los cambios legales en la segunda mitad del siglo xIx. El memorial muestra que los dueños de Estancita usaron esa estrategia en Gamotes, y para la época de las compañías deslindadoras ya habían consolidado su posesión, como vimos anteriormente. Sin duda también recurrieron a sus contactos en los gobiernos estatal y nacional, por lo que representaban un adversario prácticamente invencible: "Todo esfuerzo para reclamar nuestra heredad ha sido inútil, porque los invasores tenían vínculos de parentesco cercano con el Gobernador del estado o relaciones imposibles de quebrantar para nosotros".${ }^{83}$ Era el mismo acceso a informaciones privilegiadas, o a los círculos de poder y decisión del que disfrutaba Arguinzóniz.

En el memorial la parte de los representantes de Lagunillas fue breve. Al igual que los otros citaron una concesión virreinal a la misión de San Antonio de Lagunillas: cuatro sitios de ganado mayor, dada por el conde de Galve en $1692 .{ }^{84}$ Luego denunciaron que los dueños de la hacienda de Tampot o Tanlacut, encabezados por Florencio Ortiz, invadieron "de manera violenta la parte SE de nuestras tierras”, quitándoles

${ }^{82}$ Véase el caso de Tampamolón, pueblo ubicado en la Huasteca potosina, que perdió los terrenos que arrendaba de la familia Santos, que fue su arrendataria. Fajardo PeÑa, "La privatización de la tierra”, pp. 108, 109. ${ }^{83}$ CCJSLP, JD, A, núm. 51, Juicio de amparo solicitado por el Lic. Wistano Luis Orozco contra el juez de primera instancia de Alaquines, por orden de aprehensión, México, marzo de 1907, f. 25v.

${ }^{84}$ El virrey Conde de Galve debió tratar con varias denuncias de las misiones franciscanas contra los estancieros. Rangel Silva, "Pames, estancieros”, pp. 241-246. 
el sitio conocido como Carrizal Grande en "días de revolución”, y que también habían sido afectados por Miguel Jaló, descendiente de Ortiz. Aseguraban, además, que la parte oriente de sus tierras les fue arrebatada por Arguinzóniz en 1897 "bajo los procedimientos violentos que quedan anotados al hablar de la comunidad de Guayabos". 85

Los últimos en aparecer en el memorial fueron los representantes de La Palma. Citaron una merced dada por el conde de Galve en 1692, y refrendada en 1696, que otorgaba "como diez sitios de ganado mayor" a la misión de San Francisco Escojhoaa (su nombre original en pame). Además de describir los límites establecidos en el documento virreinal, tuvieron el cuidado de añadir que su título señalaba que la misión pertenecía a la Custodia de San Salvador de Tampico y a la "Alcaldía mayor de la villa de Santiago de los Valles y Minas de Guadalcazar". Datos que sólo un especialista en la historia colonial sabría, o bien quien tuviera a la vista el documento original. ${ }^{86}$ Los de La Palma también acusaron a los dueños de la hacienda Estancita de apropiarse de las tierras de los lados poniente y norte "en tiempos de revolución [...] en usurpación desnuda sin formalidades de ninguna especie". Mientras que por el sur y el oriente el licenciado Manuel Medina tomó, con el apoyo de tropa armada, otra gran área de terreno a nombre de Manuel González en 1882. ${ }^{87}$ Ya sabemos de la lucha

${ }^{85}$ CCJSLP, JD, A, núm. 51, Juicio de amparo solicitado por el Lic. Wistano Luis Orozco contra el juez de primera instancia de Alaquines, por orden de aprehensión, México, marzo de 1907, ff. 25v., 26.

${ }^{86}$ Para la historia de la custodia franciscana de Tampico consúltese Noyola 1988; y para una etnohistoria de los pames en las misiones RANGEL Silva, "Pames, estancieros".

${ }^{87}$ Manuel González fue presidente de México de 1880 a 1884, amigo 
presentada en 1891 y de cómo los conflictos internos echaron atrás aquel esfuerzo. El memorial nos da a conocer que la gente de La Palma presentó una reclamación judicial por medio de Vicente Salazar, y ya habían pasado diez años sin ningún resultado. Ante estos hechos se quejaron de manera amarga y elocuente:

[...] hemos sido despojados de nuestros bienes por hombres opulentos y poderosos, $\mathrm{y}$ tenemos de hecho, cerradas todas las puertas en el Estado para reclamar nuestros derechos y reivindicar nuestras tierras, pues el Supremo tribunal de Justicia por la sentencia que dictó su $1^{\text {a }}$ Sala en 23 de julio último, nos reduce a la condición de cosas ilotas o parias puestos fuera de los derechos civiles o concedidos a los demás hombres; y el remedio de la Justicia federal no existirá para nosotros mientras permanezca al frente del Juzgado de Distrito de este Estado el antiguo y temible verdugo de las comunidades de indígenas. ${ }^{88}$

Los representantes de La Palma parecen haber sido más experimentados en el uso de lenguajes políticos, pues buscaban producir simpatía por sus sufrimientos, e indignación contra quienes les hacían daño. Con base en sus experiencias de las últimas décadas querían que se entendiera que las estructuras de administración de justicia locales, estatales y federales, les eran como una muralla infranqueable de leyes, de jurisprudencia generada por las cortes, y de individuos encargados de impartir justicia y aplicar la ley. En

cercano de Porfirio Díaz y gran propietario en Tamaulipas y en la zona media de San Luis. Garner, Porfirio Díaz, pp. 111-115.

${ }^{88}$ CCJSLP, JD, A, núm. 51, Juicio de amparo solicitado por el Lic. Wistano Luis Orozco contra el juez de primera instancia de Alaquines, por orden de aprehensión, México, marzo de 1907, f. 27. 
medio de su desesperación (por "los padecimientos de toda una raza”), declararon que habían optado por el camino de la paz para apelar al presidente de la República para que él, como máxima autoridad: "En ejercicio de un poder más alto que el de los ricos que nos han despojado y que el de todas las autoridades que nos han menospreciado, tenga a bien extender a nuestro favor su mano paternal y bienhechora". ${ }^{89}$

Era la añoranza de un poder paternalista favorable a las comunidades como anhelo político que impulsaba el reclamo escrito dirigido a un político liberal, ${ }^{90} \mathrm{en}$ un mundo donde las comunidades parecían un anacronismo en todos los sentidos. Por eso es tan interesante el memorial, como expresión de los reclamos y anhelos políticos de varios grupos de indígenas, como reminiscencia de formas políticas basadas en los moldes liberales, y como testimonio escrito de una narrativa histórica que nutría su discurso político. La narrativa indígena sustentaba su trama en las concesiones coloniales hechas por reyes, virreyes y jueces de composición, esto es en documentos legalmente reconocibles por cualquier juzgado. Además insistía en cada caso en que las tierras habían estado en una posesión pacífica por siglos, y enfatizaba los violentos despojos ocurridos en las últimas décadas, además de la indiferencia o la abierta hostilidad de los jueces contemporáneos.

${ }^{89}$ CCJSLP, JD, A, no. 51, Juicio de amparo solicitado por el Lic. Wistano Luis Orozco contra el juez de primera instancia de Alaquines, por orden de aprehensión, México, marzo de 1907, f. 27.

90 También le solicitaron a Díaz que se nombrara un juez de distrito no ligado a los hacendados, ni de actitud antiindígena, CCJSLP, JD, A, núm. 51, Juicio de amparo solicitado por el Lic. Wistano Luis Orozco contra el juez de primera instancia de Alaquines, por orden de aprehensión, México, marzo de 1907, f. 8. 
Orozco reconoció las dificultades que implicaba dar a conocer un documento así al presidente, por lo que se lo pensó un mes completo mientras decidía qué hacer. El paternalismo no caracterizaba a las acciones de Díaz. ${ }^{11}$ Finalmente el experto decidió enviar el documento, que tuvo las consecuencias judiciales que podían esperarse. Los grupos de interés acomodados al orden liberal no admitirían que se buscara una vía de apelación y negociación diferente de las ya establecidas.

\section{EL PROCESO JUDICIAL Y EL PESO DEL PODER}

Para el juez de Alaquines, el artículo 85 de la Constitución federal, el 38 de la Ley de Terrenos Baldíos y el artículo 46 de su reglamento no aplicaban como soporte legal para el documento enviado a Díaz, ya que se trataba de "inmuebles de naturaleza diversa a los que esas disposiciones aluden", y de un asunto controvertido que sólo el poder judicial podía decidir, por lo que el presidente era una autoridad incompetente para conocerlo o intervenir. Así que el memorial tenía como único objetivo posible el desprestigio de las personas mencionadas en él, con lo cual también se demostraba la evidente intención dolosa requerida por la ley. Como uno de los testigos requeridos por el juez, Vicente Salazar, declaró que fue Orozco quien escribió el documento, entonces se hizo responsable y reo del delito de difamación al originario de Jalisco. ${ }^{92}$ En los interrogatorios a los individuos que apare-

${ }^{91}$ Díaz recibió muchas peticiones, pero no se conducía paternalmente para resolverlas. MARINo, “Ahora que Dios nos ha dado padre”, p. 1368. ${ }_{92}$ CCJSLP, JD, A, núm. 51, Juicio de amparo solicitado por el Lic. Wistano Luis Orozco contra el juez de primera instancia de Alaquines, por orden de aprehensión, México, marzo de 1907, f. 31. 
cieron como firmantes y representantes de las comunidades, la mayoría negó haber firmado el documento, y hasta tener conocimiento de los hechos violentos relatados en el memorial. Algunos eran arrendatarios de Arguinzóniz y dijeron enterarse por boca de éste del proceso judicial, incluso que la gente de Guayabos se había arreglado pacíficamente con Arguinzóniz por las cuestiones de sus tierras. ${ }^{93}$

El proceso seguido en el juzgado fue impecable en cuanto a las formas requeridas, y la orden de aprehensión contra Orozco aparecía perfectamente justificada por las retractaciones de los firmantes del memorial. Pero ésa es la máscara legal que encubre maniobras políticas y prácticas intimidatorias. Como lo dijo uno de los testigos que se retractó: fue el mismo senador Arguinzóniz quien le comentó del pleito judicial. Seríamos ingenuos si pensáramos que esas pláticas entre el senador y sus arrendatarios se daban de igual a igual, amistosamente. ¿Y si aparecían como firmantes en el memorial? Las conversaciones entre el hombre poderoso, el patrón, y aquellos que podían perderlo todo debieron ser por lo menos intimidantes. Después de esas pláticas, informativas en todos los sentidos para los jornaleros, ellos comparecían ante el juez quien, antes de interrogarlos, les leía la demanda por difamación de Arguinzóniz contra los posibles autores del memorial, y se les recordaban cuáles eran las penas por dar falso testimonio ante un juez. Pocos labradores o arrendatarios podrían haber sido indiferentes ante ese proceso judicial, una manifestación intimidante del poder.

93 CCJSLP, JD, A, núm. 51, Juicio de amparo solicitado por el Lic. Wistano Luis Orozco contra el juez de primera instancia de Alaquines, por orden de aprehensión, México, marzo de 1907, ff. 32-34. 
Aun así hubo quien confirmó, aunque fuera parcialmente, cómo fue que se hizo el memorial. Uno de los testigos, un labrador de Lagunillas llamado Serapio Solís, después de que le dieron a conocer "las penas del testigo que se condujere con falsedad", testificó de esta manera:

Me parece que un día del mes de agosto del año próximo pasado había venido yo a este lugar a tratar unas mulas, y me encontré aquí con varios indígenas de las comunidades de Lagunillas, Guayabos, Santa María y Gamotes, y Pablo Martínez, apoderado de los de Lagunillas me encontró por la noche (pues nos quedamos juntos en la plazuela del rancho), y me dijo y me enseñó, porque él traía un ocurso igual al que se me acaba de dar lectura, por lo menos en la parte relativa a la comunidad de Lagunillas, que fue lo que me dio a conocer Pablo, diciéndome que lo había hecho el Lic. Don Wistano L. Orozco y que iba al señor Presidente de la República con objeto que nos volvieran los terrenos que hace tiempo venimos reclamando sin resultado, yo que he visto que todos nuestros esfuerzos han resultado infructuosos para conseguir lo que deseamos, y que estimé imposible dirigirme a una personalidad de tal naturaleza y a la vez eficaz intervención, convine en firmar al día siguiente. ${ }^{94}$

Sin embargo, aseguró que a nadie de Lagunillas habían encarcelado a causa de los pleitos por las tierras, ni habían sido multados. Respecto de lo relatado por la gente de Guayabos, Solís dijo que sabía que un Ramón Reyes había estado en la cárcel de Alaquines por quejarse de Arguinzóniz, porque el mismo Reyes se lo había contado, pero nada más. Otro tes-

${ }^{94}$ CCJSLP, JD, A, núm. 51, Juicio de amparo solicitado por el Lic. Wistano Luis Orozco contra el juez de primera instancia de Alaquines, por orden de aprehensión, México, marzo de 1907, ff. 38, 38v. 
tigo que no se retractó por completo fue Isidro Yáñez, de la comunidad de Guayabos (él vivía en el rancho del Saucillito). Reconoció que desde enero de 1906 le habían dado poder legal a Orozco para que "nos reclamase nuestras tierras". Junto con representantes de su pueblo y de los otros mencionados en el memorial concurrieron a ver a Orozco y a firmar el ocurso. Recordó que ese día había más de 60 individuos reunidos de las diferentes comunidades, pero que él, Isidro Yáñez, sólo firmó por el reclamo de las tierras despojadas a su padre, José Yáñez, a quien se le habían cobrado 150 pesos que no quiso pagar por considerarlo injusto, además de que aseguró ser cierto que le habían quitado 100 cargas de maíz. Testificó que mucho de lo que se decía en la parte que correspondía a Guayabos era cierto, pero negó saber de los otros testimonios. Supo por comentario de la señora Herminia Urías, quien había hospedado a Orozco en Alaquines cuando se hizo la firma del ocurso, que éste le había escrito para asegurarle que el documento ya había llegado al presidente Díaz. ${ }^{95}$

El jornalero de Lagunillas, Pablo Martínez, indígena de 62 años, también confirmó haber firmado el ocurso escrito por Orozco, "con la representación de gerente de la comunidad de indígenas de nuestro pueblo", y de hecho aceptó haber dado algunos de los datos mencionados en el mismo. Por ejemplo, la pérdida de terrenos de Lagunillas "en tiempos de la revolución” y a manos de Florencio Ortiz primero, y Miguel Jalón después. Por supuesto que Martínez tuvo

95 CCJSLP, JD, A, núm. 51, Juicio de amparo solicitado por el Lic. Wistano Luis Orozco contra el juez de primera instancia de Alaquines, por orden de aprehensión, México, marzo de 1907, ff. 39-40. 
el cuidado de recalcar que no tenía motivo de queja contra Antonio Arguinzóniz. ${ }^{96}$ De Santa María Acapulco el jornalero Pascual Rodríguez ratificó que Arguinzóniz y los señores Olvera habían despojado a su pueblo de parte de sus tierras "pero ninguno ha empleado medios violentos", y aseguró que Orozco era el autor del escrito "porque ni yo ni nadie de los demás firmantes somos capaces para ello”. Además Orozco había modificado su relato porque en el caso del castigo de trabajo en la iglesia, fue por un día y no por un mes. ${ }^{97}$

El proceso judicial mantuvo la solidez requerida por las formas y la ley, además de desplegar el peso de su capacidad punitiva sobre los jornaleros de la zona, que ante esa representación del poder aparecían como simples individuos sin elementos con qué hacer valer sus derechos. Aun así, algunos de ellos lograron deslizar por aquí y por allá su verdad: fueron despojados, perdieron buena parte de sus tierras, sufrieron castigos injustos sus representantes comunitarios; todo ello envuelto en la "verdad" que el poder quería asentar judicialmente: que los jornaleros, los pames, eran unos individuos ignorantes, sin capacidad de articular de forma coherente una oposición colectiva a las injusticias, por lo que el único culpable era el abogado fuereño, que se aprovechó de su "rusticidad".

Así que, en el informe rendido al juez de distrito el 14 de marzo de 1907, el juez Gómez señaló que el memorial care-

${ }^{96}$ CCJSLP, JD, A, núm. 51, Juicio de amparo solicitado por el Lic. Wistano Luis Orozco contra el juez de primera instancia de Alaquines, por orden de aprehensión, México, marzo de 1907, ff. 41, 41v.

${ }^{97}$ CCJSLP, JD, A, núm. 51, Juicio de amparo solicitado por el Lic. Wistano Luis Orozco contra el juez de primera instancia de Alaquines, por orden de aprehensión, México, marzo de 1907, f. 42. 
cía de cualquier base legal al haberse dirigido al presidente de México, por tratarse de un asunto contencioso de tierras. Su único objeto era la difamación, porque además de que la mayoría de los involucrados se retractó de la firma, o de haber consentido en el objeto del ocurso, el autor del documento, Wistano L. Orozco, había confesado, "tácitamente", tener enemistad casi mortal con su acusador al señalar que Arguinzóniz lo había retado a duelo. ${ }^{98}$ Señaló el juez que incluso hubo quienes se presentaron "espontáneamente" al juzgado en los días en que se hicieron los interrogatorios, como Severiano González de la Palma, que dijo:

Que había sabido con sorpresa que en el libelo elevado al señor Presidente a nombre de varias comunidades, apareció firmado por los indígenas de La Palma, lo cual siendo de todo punto falaz, pues él hasta ahora tiene conocimiento de ello, para evitar que de una manera sumatisada [sic] se le estime complicado en este negocio se apresuraba a hacerlo saber. ${ }^{99}$

Según el juez de primera instancia, Wistano L. Orozco era culpable no sólo de elevar una solicitud infructuosa a quien no correspondía en términos legales, sino que ese documento estaba plagado de "imputaciones perfectamente deshonrosas contra un enemigo mortal”, por eso se presumía la existencia de la intención dolosa del ocurso y se había

${ }^{98}$ CCJSLP, JD, A, núm. 51, Juicio de amparo solicitado por el Lic. Wistano Luis Orozco contra el juez de primera instancia de Alaquines, por orden de aprehensión, México, marzo de 1907, ff. 54-55.

${ }^{99}$ CCJSLP, JD, A, núm. 51, Juicio de amparo solicitado por el Lic. Wistano Luis Orozco contra el juez de primera instancia de Alaquines, por orden de aprehensión, México, marzo de 1907, f. 56. 
librado la orden de arresto en su contra. ${ }^{100} \mathrm{El} 18$ de marzo el juez de distrito, Tomás Ortiz, por recomendación del promotor fiscal, declaró que no se suspendían los actos reclamados por Orozco; es decir, no se detenía el proceso judicial en Alaquines. ${ }^{101}$ De inmediato Orozco, por medio de Nicolás Carreño, solicitó la revisión del auto del juez de distrito ante la Suprema Corte de Justicia de la Nación. Para entonces la esposa de Orozco, Teresa Sánchez de Orozco, también fungía como su representante en el juzgado de distrito. ${ }^{102}$

El 23 de abril de 1907 la Corte Suprema dictaminó, por unanimidad de votos, estar de acuerdo con el juez de distrito y se negó a conceder la suspensión del auto del juez de Alaquines contra Orozco, porque a su criterio el caso no estaba contemplado en el artículo 784 del Código Federal de Procedimientos Civiles. ${ }^{103} \mathrm{El}$ juez de distrito en San Luis Potosí falló el 27 de julio de 1907 que no amparaba a Orozco contra los actos del juez de Alaquines, en especial contra la orden de aprensión ya que, según el artículo 289 del Código de Procedimientos Penales, si se sospechaba que una persona tenía responsabilidad criminal de un delito, se debía proceder a su

100 CCJSLP, JD, A, núm. 51, Juicio de amparo solicitado por el Lic. Wistano Luis Orozco contra el juez de primera instancia de Alaquines, por orden de aprehensión, México, marzo de 1907, ff. 56, 56v.

101 CCJSLP, JD, A, núm. 51, Juicio de amparo solicitado por el Lic. Wistano Luis Orozco contra el juez de primera instancia de Alaquines, por orden de aprehensión, México, marzo de 1907, ff. 58, 58v.

102 CCJSLP, JD, A, núm. 51, Juicio de amparo solicitado por el Lic. Wistano Luis Orozco contra el juez de primera instancia de Alaquines, por orden de aprehensión, México, marzo de 1907, ff. 61, 61v.

103 CCJSLP, JD, A, núm. 51, Juicio de amparo solicitado por el Lic. Wistano Luis Orozco contra el juez de primera instancia de Alaquines, por orden de aprehensión, México, marzo de 1907, ff. 64, 64v. 
detención, y eso era lo que había hecho el juez de primera instancia. ${ }^{104}$ Conforme al procedimiento, el juez envió de nuevo su dictamen a la Suprema Corte para su revisión; la Suprema Corte resolvió con una ejecutoria el 18 de diciembre de 1908; lamentablemente, en el expediente de la Casa de la Cultura Jurídica de San Luis Potosí no aparece tal ejecutoria. Como sea, al desechar los argumentos de Orozco el sistema judicial desestimó los argumentos expuestos en el memorial por las comunidades. De esa forma, amparada en el manto de una perfecta legalidad, la oligarquía porfirista eliminó cualquier posibilidad de negociación con un sector reacio a aceptar la situación prevaleciente. En lugar de negociación apareció la coerción en las amenazas veladas a quienes manifestaron su postura política en el memorial y en los diferentes actos de resistencia anteriores, presionándolos para que se retractaran o para castigarlos con prisión si se negaban.

El memorial como solicitud de tierras "proindiviso" resultó infructuoso por la forma como los jueces interpretaron el orden judicial, que aunque estaba en proceso de conformación acorde con las siempre cambiantes reglas liberales, tenía como una premisa inamovible la inexistencia de personalidades jurídicas corporativas, así sus reclamos fueran justos y razonables o no. Es decir, la legitimidad de una petición se definía por el cumplimiento o no de las condiciones estipuladas por las garantías individuales, y no por las condiciones reales en que se daban las relaciones de poder.

104 CCJSLP, JD, A, núm. 51, Juicio de amparo solicitado por el Lic. Wistano Luis Orozco contra el juez de primera instancia de Alaquines, por orden de aprehensión, México, marzo de 1907, ff. 66v-75v. 


\section{REFLEXIONES FINALES}

El testimonio que los indígenas dieron a Wistano L. Orozco en 1906 describe las presiones sobre las tierras y las comunidades en las últimas décadas del siglo XIX. Tales presiones han sido relativamente poco estudiadas en San Luis Potosí, pese a ser el escenario de donde Wistano Orozco sacaba sus ideas sobre los problemas de la tierra en México. ${ }^{105}$ Como hemos visto, las presiones venían tanto de los cambios al marco legal como de acciones ilegales. El memorial deja ver la obstinada apelación de los pames a los papeles coloniales y los procesos jurídicos, y fue una continuación de la tradición colonial de defensa en los tribunales de los derechos de las comunidades, acomodada a los lenguajes del liberalismo porfirista, a pesar de que las posibilidades de victoria eran reducidas o prácticamente nulas. El memorial no surgió de la nada; las luchas por las tierras y la viabilidad misma de las comunidades se dio durante todo el siglo XIX y el periodo porfirista fue especialmente conflictivo; en ese contexto es un valioso testimonio de esas luchas desde el punto de vista de las comunidades. También nos deja ver la existencia de una identidad grupal más allá de los límites locales de cada pueblo, identidad porosa y volátil, como cualquier otra, que a veces desaparecía detrás de la máscara de la sumisión al orden.

Pero el memorial no es sólo un testimonio, sino una propuesta de negociación de los pames como un actor colectivo,

105 Por ejemplo, Ankerson revisó el caso del condueñazgo de los Moctezuma, en el que había elementos de abuso y descontento pero, al no lograr identificar otros casos similares, supuso que "la atmósfera que prevalecía en el campo en el último decenio del porfiriato era de estabilidad social”. Ankerson, El caudillo agrarista, pp. 16-20. 
que no deseaban quedar fuera de los parámetros de legitimidad del orden liberal; a pesar de más de medio siglo de esfuerzos infructuosos seguían dispuestos a negociar con el Estado porfirista o con los grandes propietarios. Esa propuesta obvió las estructuras políticas y judiciales del estado potosino, totalmente cerradas a cualquier negociación de ese tipo. El memorial era también parte de una pieza jurídica manejada por un habilidoso abogado, Wistano Orozco, experto en la legislación sobre tierras y en la lucha en los tribunales, pero que cálculo mal las consecuencias políticas y jurídicas de su acto.

¿Qué nos dice este caso de la cultura política de la época? En términos legales las comunidades no existían y no podían reclamar nada, pero lo hicieron. Así que la cultura política no se definía por el marco legal, sino por las acciones y los discursos de los actores. Eso lo tenían claro todos: los grandes propietarios accedían a informaciones valiosas y emprendían acciones con ventaja sobre sus interlocutores, intimidaban a quienes pudieran cuestionarlos y usaban el poder político en su beneficio. Los jornaleros, arrendatarios y campesinos lo sabían también, y mientras mantenían las luchas legales, apelaban ilegalmente al máximo poder, se retractaban de sus afirmaciones más comprometedoras y contribuían a la apariencia del orden. Las acciones de un senador al enterarse de un documento que lo perjudicaba no eran diferentes de las de un jornalero que suscribía un ocurso dirigido al presidente Díaz; actuaban de la misma forma, buscando recovecos, ventajas, argumentos, discursos y acciones que les permitieran conseguir sus propósitos o por lo menos negociarlos. Las acciones podían ser ilegales y legítimas al mismo tiempo. Los resultados eran desiguales dadas 
las diversas condiciones de los actores, y las injusticias continuaban irresueltas mientras el orden liberal mantenía la máscara de la legalidad y la modernidad. Era una cultura política compartida por todos, utilizada por todos y aceptada por todos, aunque estuvieran en desacuerdo en los detalles que afectaban a cada uno.

\section{SIGLAS Y REFERENCIAS}

AGN, G, SI Archivo General de la Nación, Gobernación, Segundo Imperio, México D. F.

AGN, $T$ Archivo General de la Nación, Tierras, México D. F. CCJSLP, JD, A Casa de la Cultura Jurídica sede San Luis Potosí, Juzgado de Distrito, Amparo, San Luis Potosí, S. L. P.

CCSLP, JD, C Casa de la Cultura Jurídica sede San Luis Potosí, Juzgado de Distrito, Civil, San Luis Potosí, S. L. P.

Aguilar-Robledo, Miguel

"Los condueñazgos del oriente de San Luis Potosí, México, de finales del siglo xIX a principios del siglo xx: algunas reflexiones teóricas”, en Vetas, II: 4 (2000), pp. 151-189.

Ankerson, Dudley

El caudillo agrarista. Saturnino Cedillo y la Revolución Mexicana en San Luis Potosí, México, Gobierno del Estado de San Luis Potosí, Instituto Nacional de Estudios Históricos de la Revolución Mexicana, Secretaría de Gobernación, 1994.

Arrioja Díaz Viruell, Luis Alberto

"Conflictos por tierras y pesquisas documentales en el Valle de Oaxaca, 1912”, en Arrioja y Sánchez, pp. 185-213.

Arrioja Díaz Viruell, Luis Alberto y Carlos Sánchez Silva (eds.) Conflictos por la tierra en Oaxaca. De las reformas borbónicas a la reforma agraria, México, El Colegio de Michoacán, Universidad Autónoma Benito Juárez de Oaxaca, 2012. 
Ávila Quijas, Aquiles, Jesús Gómez Serrano, Antonio Escobar OHMstede y Martín SÁnchez (coords.) Agua y tierra. Negociaciones, acuerdos y conflictos en México, siglos XIX y XX, México, El Colegio de Michoacán, Centro de Investigaciones y Estudios Superiores en Antropología Social, Universidad Autónoma de Aguascalientes, 2009.

BAKer, Keith Michael

Inventing the French Revolution. Essays on French Political Culture in the Eighteenth Century, Nueva York, Cambridge University Press, 1990.

Carmagnani, Marcello (coord.)

Constitucionalismo y orden liberal. América Latina, 18591920, Turín, Otto Editore, 2000.

"Introducción", en Carmagnani, 2000, pp. 1-7.

Connaughton, Brian

“Introducción”, en Connaughton (coord.), 2003.

Connaughton, Brian (coord.)

Poder y legitimidad en México en el siglo XIX. Instituciones y cultura política, México, Universidad Autónoma Metropolitana-Iztapalapa, Consejo Nacional de Ciencia y Tecnología, Miguel Ángel Porrúa, 2003.

Prácticas populares, cultura política y poder en México, siglo XIX, México, Universidad Autónoma Metropolitana-Iztapalapa, Juan Pablos, 2008.

Escobar, Antonio

"La ciudadanía en México en la primera mitad del siglo xix ¿para quién?”, en Escobar OHMSTEde, Mandrini y OrtelLI (eds.), 2007, pp. 65-80.

"Estudio introductorio. Haciendas, pueblos y recursos naturales en San Luis (1856-1916)”, en Escobar y GutiÉrRez, 2009, pp. 19-98. 
"Tierra y agua en el oriente potosino de la segunda mitad del siglo xix”, en Ávila, Gómez, Escobar ohmstede y SánCHEZ, 2009, pp. 81-114.

Escobar ohmstede, Antonio (coord.)

Los pueblos indios en los tiempos de Benito Juárez, México, Universidad Autónoma Metropolitana, Universidad Autónoma Benito Juárez de Oaxaca, 2007.

Escobar ohmstede, Antonio, Romana Falcón y Raymond Buve (comps.)

Pueblos, comunidades y municipios frente a los proyectos modernizadores en América Latina, San Luis Potosí, Centro de Estudios y Documentación de Latinoamérica, El Colegio de San Luis, 2002.

Escobar Ohmstede, Antonio y Ana María Gutiérrez

"El liberalismo y los pueblos indígenas en las Huastecas, 18561885”, en Escobar Ohmstede (coord.), 2007, pp. 253-297.

Escobar Ohmstede, Antonio y Ana María Gutiérrez (coords.)

Entretejiendo el mundo rural en el oriente de San Luis Potosí, siglos XIX y XX, México, Centro de Investigaciones y Estudios Superiores en Antropología Social, El Colegio de San Luis, 2009.

Escobar Ohmstede, Antonio, Raúl J. Mandrini y Sara Ortelli (eds.)

Sociedades en movimiento. Los pueblos indígenas de América Latina en el siglo XIX, Buenos Aires, Universidad Nacional del Centro de la Provincia de Buenos Aires, 2007.

Escobar, Antonio y José Alfredo Rangel (coords.)

Haciendas, negocios y politica en San Luis Potosí, siglos XVIII al XX, México, El Colegio de San Luis, 2011.

Fajardo Peña, Gabriel

"La privatización de la tierra y problemas agrarios en la Huasteca potosina, 1870-1920”, en Escobar y GutiérRez (coords.), 2009, pp. 99-135. 
FALCón, Romana

Revolución y caciquismo. San Luis Potosí, 1910-1938, México, El Colegio de México, 1984.

"Subterfugios y deferencias. Indígenas, pueblos y campesinos ante el segundo imperio", en Escobar, Falcón y Buve (comps.), 2002, pp. 125-143.

"Litigios interminables. Indígenas y comuneros ante la justicia agraria liberal (1857-1828)”, en MANDRINI, EscoBAR y ORTELli (eds.), 2007, pp. 81-97.

"Indígenas y justicia durante la era juarista. El costo social de la "contribución de sangre" en el Estado de México", en Escobar Ohmstede (coord.), 2007, pp. 123-150.

"Desamortización a ras de suelo, ¿el lado oculto del despojo? México en la segunda mitad del siglo xix", en Ponce y PÉreZ, 2009.

Formisano, Ronald P.

"The Concept of Political Culture", en The Journal of Interdisciplinary History, 31: 3 (invierno 2001), pp. 393-426.

Fraser, Donald J.

"La política de desamortización en las comunidades indígenas, 1856-1872", en Historia Mexicana, xxi: 4 (84) (abr.-jun. 1972), pp. 615-652.

Garner, Paul

Porfirio Diaz: del héroe al dictador. Una biografía política, México, Planeta, 2010.

Granados García, Aymer

"Comunidad indígena, imaginario monárquico, agravio y economía moral durante el segundo imperio mexicano", en Secuencia, 41 (1998), pp. 45-73.

Guardino, Peter

Peasants, Politics, and the Formation of México's National State. Guerrero 1800-1857, Stanford, Stanford University Press, 1996. 
El tiempo de la libertad. La cultura politica popular en Oaxaca, 1750-1850, Oaxaca, Universidad Autónoma Metropolitana, Universidad Autónoma Benito Juárez de Oaxaca, El Colegio de Michoacán, El Colegio de San Luis, H. Congreso del estado de Oaxaca, 2009.

Guarisco, Claudia

"Indios, cultura y representación política durante el primer federalismo. El caso del Valle de México", en Connaughton (coords.), 2008, pp. 167-221.

Gutiérrez, Ana María

"El condueñazgo de los Moctezuma. Origen y defensa de la tierra, 1880-1929”, en Escobar y GutiérRez, 2009, pp. 237-262.

Holden, Robert

Mexico and the Survey of Public Lands. The Management of Modernization 1876-1911, DeKalb, Ill.,Northern Illinois University Press, 1994.

Iracheta, P. y Diana Birrichaga (comps.)

A la sombra de la primera república federal. El Estado de México, 1824-1835, Toluca, El Colegio Mexiquense, 1999.

Kourí, Emilio

Un pueblo dividido. Comercio, propiedad y comunidad en $\mathrm{Pa}$ pantla México, México, Fondo de Cultura Económica, El Colegio de México, 2013.

Kuntz Ficker, Sandra (coord.)

Historia económica general de México. De la colonia a nuestros días, México, El Colegio de México, Secretaría de Economía, 2010.

Levin, Diana y Federico Navarrete (eds.)

Indios, mestizos y españoles. Interculturalidad e historiografía en la Nueva España, México, Universidad Autónoma Me- 
tropolitana-Azcapotzalco, Universidad Nacional Autónoma de México, 2007.

Lira GonzÁlez, Andrés

Comunidades indígenas frente a la ciudad de México. Tenochitlan y Tlatelolco, sus pueblos y barrios, 1812-1919, México, El Colegio de México, El Colegio de Michoacán, Consejo Nacional de Ciencia y Tecnología, 1983.

Marino, Daniela

"La modernidad a juicio: los pueblos de indígenas en la transición jurídica. Huixquilucan, Estado de México, 1856-1911”, tesis de doctorado en historia, México, El Colegio de México, 2004.

"Ahora que Dios nos ha dado padre... El segundo imperio y la cultura jurídico-política campesina en el centro de México", en Historia Mexicana, Lv: 4 (220) (abr.-jun. 2006), pp. 1353-1410.

Marino, Daniela y Cecilia Zuleta

"Una visión del campo. Tierra, propiedad y tendencias de la producción, 1850-1930”, en Kuntz Ficker (coord.), 2010.

Menegus Bornemann, Margarita

"La desamortización de bienes comunales y municipales en el valle de Toluca (1800-1854)", en Iracheta y Birrichaga (comps.), 1999, pp. 279-297.

Orozco, Wistano Luis

Los negocios sobre tierras públicas. Contestaciones al Sr. Lic. D. Genaro B. Ramírez por el Lic. Wistano L. Orozco en el caso especial de Beas y Socios, Guadalajara, Imprenta de Ancira y Hno. A. Ochoa, 1895.

Legislación y jurisprudencia sobre terrenos baldios, edición facsimilar de la de 1895, México, Ediciones El Caballito, 1974.

Los ejidos de los pueblos, México, Ediciones El Caballito, 1975. 
PANI, Erika

“¿Verdaderas figuras de Cooper' o 'pobres inditos infelices’? La política indigenista de Maximiliano”, en Historia Mexicana, XLVII: 3 (187) (ene.-mar. 1998), pp. 571-604.

Para mexicanizar el segundo imperio. El imaginario politico de los imperialistas, México, El Colegio de México, Instituto de Investigaciones Dr. José María Luis Mora, 2001.

Pérez Toledo, Sonia

"Movilización social y poder político en la Ciudad de México en la década de 1830”, en Connaughton (coord.), 2008, pp. 335-367.

Piccato, Pablo

“'El populacho’ y la opinión pública: debates y motines sobre la deuda inglesa en 1884”, en Connaughton (coord.), 2003, pp. 531-579.

Ponce Alcocer, María Eugenia y Laura Pérez Rosales (coords.)

El oficio de una vida. Raymond Buve, un historiador mexicanista, México, Universidad Iberoamericana, 2009.

Radding, Cynthia

"Paisajes poscoloniales. Comunidades indígenas, espacios políticos y ciudadanía truncada en dos fronteras hispanoamericanas”, en Sociedades en movimiento. Anuario del IEHS, suplemento 1, 2007, pp. 157-172.

Rangel Silva, José Alfredo

"Pames, estancieros y franciscanos en Rioverde, Valles y sur de Nuevo Santander, 1600-1800”, en Relaciones. Estudios de historia y sociedad, 30: 120 (2009), pp. 225-266.

"Transformaciones en la propiedad agraria. El caso de la hacienda de Cárdenas, 1800-1940”, en Rangel y Camacho (coords.), 2012. 
Rangel Silva, José Alfredo y Hortensia Camacho (coords.)

La propiedad rural en México en los siglos XIX y XX. Enfoques económicos y políticos, México, El Colegio de San Luis, 2012.

Ricoeur, Paul

Tiempo y narración I. Configuración del tiempo en el relato histórico, México, Siglo Veintiuno Editores, 2000.

Riguzzi, Paolo

"Libre cambio y libertad económica en la experiencia liberal mexicana, 1850-1896”, en CARMAgNani (coord.), 2000, pp. 287-314.

Ríos ZÚÑIga, Rosalía

"Popular Uprising and Political Culture in Zacatecas: The Sombrerete Uprisings (1829)", en The Hispanic American Historical Review, 87:3 (2007), pp. 499-536.

Ruiz Medrano, Ethelia

"El espejo y su reflejo: títulos primordiales de los pueblos indios utilizados por españoles en Tlaxcala, siglo XVIII", en LEvin y Navarrete, 2007.

Serna, Ana María

Manuel Peláez y la vida rural en la Faja de Oro. Petróleo, revolución y sociedad en el norte de Veracruz, 1910-1928, México, Instituto de Investigaciones Dr. José María Luis Mora, 2008.

La justicia durante el porfiriato y la revolución 1898-1914. Casos que motivaban la interposición del amparo relacionados con la libertad de expresión y los delitos de difamación, calumnia e injurias, México, Suprema Corte de Justicia de la Nación, 2010.

"Casos que motivaban la interposición del amparo relacionados con la libertad de expresión y los delitos de difamación, calumnia e injurias”, en SERNA, 2010, pp. 3-26. 
Silva Prada, Natalia

"Las manifestaciones políticas indígenas ante el proceso de control y privatización de tierras: México, 1786-1856”, en Connaughton (coord.), 2003, pp. 75-135.

Somers, Margaret R.

What's political or cultural about political culture and the public sphere? Toward an historical sociology of concept formation”, en Sociological Theory, 13:2 (1995), pp. 113-144.

Uribe Soto, María de Lourdes

"La hacienda Estancita frente a la restitución de tierras del pueblo de La Palma, 1916-1923”, en Escobar y Rangel, 2011, pp. 244-247. 